Article

\title{
Modeling Urban Growth and Socio-Spatial Dynamics of Hangzhou, China: 1964-2010
}

\author{
Jian Feng and Yanguang Chen *(i) \\ Department of Geography, College of Urban and Environmental Sciences, Peking University, Beijing 100871, \\ China; fengjian@pku.edu.cn \\ * Correspondence: chenyg@pku.edu.cn
}

Citation: Feng, J.; Chen, Y. Modeling Urban Growth and Socio-Spatial Dynamics of Hangzhou, China: 1964-2010. Sustainability 2021, 13, 463. https://doi.org/su13020463

Received: 28 November 2020 Accepted: 2 January 2021 Published: 6 January 2021

Publisher's Note: MDPI stays neutral with regard to jurisdictional clai$\mathrm{ms}$ in published maps and institutional affiliations.

Copyright: (C) 2021 by the authors. Licensee MDPI, Basel, Switzerland. This article is an open access article distributed under the terms and conditions of the Creative Commons Attribution (CC BY) license (https:// creativecommons.org/licenses/by/ $4.0 /)$.

\begin{abstract}
Urban population density provides a good perspective for understanding urban growth and socio-spatial dynamics. Based on sub-district data of the five national censuses in 1964, 1982, 1990,2000 , and 2010, this paper is devoted to analyzing of urban growth and the spatial restructuring of the population in the city of Hangzhou, China. Research methods are based on mathematical modeling and field investigation. The modeling result shows that the negative exponential function and the power-exponential function can be well fitted to Hangzhou's observational data of urban density. The negative exponential model reflects the expected state, while the power-exponential model reflects the real state of urban density distribution. The parameters of these models are linearly correlated to the spatial information entropy of population distribution. The fact that the density gradient in the negative exponential function flattened in the 1990s and 2000s is closely related to the development of suburbanization. In terms of investigation materials and the changing trend of model parameters, we can reveal the spatio-temporal features of Hangzhou's urban growth. The main conclusions can be reached as follows. The policy of reformation and opening-up and the establishment of a market economy improved the development mode of Hangzhou. As long as a city has a good social and economic environment, it will automatically tend to the optimal state through self-organization.
\end{abstract}

Keywords: urban growth; urban population density; urban spatial structure; spatial entropy; suburbanization; Hangzhou

\section{Introduction}

Urban growth and the spatial restructuring of urban morphology based on population densities are some of the important issues of urban geography. With the introduction of post-modern mathematics, such as fractal geometry, and bionic mathematics, such as cellular automata [1-4], the ability to quantitatively depict and use methods of simulating experiments of urban geography are strengthened. Fractal description and computer simulation have brought and are still bringing about a revolution in the studies on urban growth and morphology. Some traditional mathematical models on urban population densities, such as Clark's model [5], were re-explained in the rise of studies on spatial complexity based on the analysis of urban systems [1,6,7]. It is noted that, until the late 1990s, the research of modeling urban population densities in developed countries is extensive, while there is much less on cities in developing countries, especially in China [8]. Since the late 1990s, research on the cities in developing countries has also made some progress in this field. Three pieces of research on urban China, with one on urban population densities in Beijing 1982-1990 by Wang and Zhou [8], one about the spatial restructuring of the population towards polycentricity in Beijing 1982-2000 by Feng et al. [9], and the last one about those in Shenyang 1982-1990 by Wang and Meng [10], brought us interesting issues and useful information about the similarities and differences between cities in China and cities in the Western Countries. Another article by Xu et al. 
tells us about how urban population density declines over time in Chinese cities from 2001 to 2015 based on the exponential model, and the authors find that initial densities and GDP growth rates influence the declining density rates [11]. Luo et al. try to model population density using a new index derived from multi-sensor image data, and then a case study is implemented using the data of Sichuan Province, China in 2015 [12]. Ren et al. performed the processing of the population density grid data of Nairobi, Kenya for 2000 and 2020, to analyze population density and spatial patterns of informal settlements based on the Clark model, the Newling model and the McMillen model [13]. In recent years, the research on urban population density and urban growth in European and American countries continues to make progress, accompanied by the improvement of methods. For example, Polinesi et al. try to reflect the relationship between population trends and urbanization in Greece by simulating density effects using a local regression approach [14]. Mariani et al. illustrates a simplified procedure identifying population sub-centers over 50 years in three Southern European cities (Barcelona, Rome, Athens) by identifying metropolitan subcenters from diachronic density-distance curves [15]. Qiang et al. provide an empirical evaluation of the classic population density functions in 382 metropolitan statistical areas (MSA) in the USA using travel times to city centers as the independent variable [16]. Moghadam et al. examine patterns of growth and change in Sydney over the time period from 1981 to 2006, taking employment density as a structural dimension, and modeling the linear and interactive effects of this dimension [17]. The results show that the urban population density distribution in both China and European-American countries complies with distance-decay law and can be described with the negative exponential function. The results also indicate that the main causes of urban growth in China in the 1980s, was at an incipient stage, unlike that in Western Countries which has been in full maturity. To get more credible knowledge about the comparison between population densities and related spatial dynamics of Chinese cities and those of the Western cities, it is necessary to conduct more empirical researches on population densities of urban China.

Urban growth is associated with the urban form (static structure) and spatial dynamics (interaction between elements). It has always been an important topic in urban studies [1,18-20]. There are two main objectives for urban growth research. One is to find the statistical laws from the macro level and describe them by mathematical modeling, and the other is to reveal the evolution mechanism from the micro level, so as to carry out empirical analysis to gain understanding and insight about city development. Anyway, scientific research includes two processes: description and understanding [21,22]. The measurements for describing urban growth include population, wealth, land-use area, and night light data. In the early years, two central variables in the study of spatial dynamics of urban evolution are population and wealth [23]. With the development of remote sensing technology, urban land area has become an important measure [20,24,25]. Recent years, night lights provide new observational data for cities [26,27]. Research perspectives involve time (processes), space (patterns), and hierarchy (size distribution), and are associated with three basic laws of geography: allometric growth law, distance-decay law, and rank-size law. Conventional mathematical modeling and quantitative analyses of urban growth are based on characteristic length. Due to the development of fractal geometry, fractal dimension and scaling exponent become important parameters for characterizing urban growth [1,2,28-33]. Using time-series of fractal dimension, we can build fractal dimension increase models to exploring spatial dynamics of urban evolution [34].

Although urban growth research can be made by using various new technologies and methods, two facts are undeniable. First, the population as a central variable for urban analysis is irreplaceable. The city is the space and place for human life. The population represents the first dynamics of urban growth [35]. Second, investigation as a basic method for urban studies is irreplaceable. Seeing is believing. Without on-the-spot investigation, it is difficult to understand the truth of a city's development [36]. Based on field research and systematic census data, this paper is devoted to research the distribution of population density in Hangzhou with the help of mathematical modeling and empirical analysis. 
Through spatio-temporal evolution of urban density distribution, we can explore the socio-spatial dynamics of Hangzhou's urban growth. The purpose is to reveal the law of urban growth in China from the perspective of population evolution. It also provides a reference for the comparison of urban development between China and the Western countries. The rest parts are organized as follows. In Section 2, the basic and new models for describing urban density are reviewed and explained, and data and method are clarified. In Section 3, empirical analyses are made for spatio-temporal evolution of Hangzhou's population density distribution patterns, and the spatial restructuring process of population are analyzed. In Section 4, several related questions are discussed. Finally, the discussion is concluded by summarizing the main points of view.

\section{Models and Methods}

\subsection{Mathematical Models}

The mathematical models of urban population density can be traced back to the early 1950s. A number of functions are proposed to characterize urban density distribution $[1,37,38]$. By making a statistical analysis of more than twenty cities, Clark found that urban population density tends to decline in a negative exponential fashion with increasing distance from the city center [5]. Clark's model can be expressed as

$$
\rho(r)=\rho_{0} e^{-b r}
$$

where $r$ is the distance, $\rho(r)$ is the population density at distance $r$ from the city center, $\rho_{0}$ is the density at the city center $(r=0), b$ is the rate at which population density declines with distance $r$. Clark's law represents the classic model for urban population density distribution. Several years after that, geography entered the stage of the Quantitative Revolution. During the period, geographers studied theoretical models with immense zeal. In the early 1960s, two new models of population density were put forward: one is a normal model by Sherratt [39] and Tanner [40], and the other is an inverse power model by Smeed [41]. The Sherratt-Tanner model can be expressed as

$$
\rho(r)=\rho_{0} e^{-b r^{2}}
$$

which is a form of Gaussian function. The model indicates that in the area far away from the city center, population density based on this model decreases much faster than that in Clark's model. Smeed's model can be express in the following form

$$
\rho(r)=K r^{-\alpha}
$$

where $K$ is the constant of proportionality, and $\alpha$ is the parameter on distance. It is easy to find that Smeed's model is not defined where $r=0$. However, Smeed's model cannot fit most of the distribution of population density. Parr once pointed out that the negative exponential function is more appropriate for describing density in the urban area, while the inverse power function is more appropriate to the urban fringe and hinterland [42]. Later, Longley and Mesev argued that the spatial distribution of population density should be depicted from two kinds of scales: Smeed's model can fit the spatial distribution of population density well when $r$ is smaller, while urban population density decreases faster than the model's expectation when $r$ is larger [43].

Sometimes, all the above models cannot reflect urban density distribution well, and more complicated models seem to be necessary. Replacing the linear equation in Clark's model with a quadratic function, Newling suggested a quadratic exponential model as follows [44]:

$$
\rho(r)=\rho_{0} e^{b r-c r^{2}}
$$

where $b$ and $c$ are parameters. Because the exponential term in Newling's model contains a multinomial equation, Newling's model can fit realistic data of population density preferably. Newling's model was treated as a more satisfactory one than that of Clark in 
describing the spatial distribution of population density. Based on Newling's model, a series of theories such as the crater effect, the tidal wave of metropolitan expansion, and the stages of urban evolution are all developed at that time [45-47]. Chen proposed a power-exponential model of urban density, which incorporates Clark's model and SherrattTanner's model directly [37]. The model can be expressed as

$$
\rho(r)=\rho_{0} e^{-b r^{\sigma}}
$$

where $\sigma$ is a parameter that reflects the changes of information entropy of urban population distribution. It can be treated as a latent scaling exponent. We will explain this in the following text. It can be seen that when $\sigma=1$, Equation (5) will reduce to Clark's model, and that when $\sigma=2$, Equation (5) will change to Sherratt-Tanner's model. Moreover, probably the lognormal distribution is also a choice [48]. The model is expressed as

$$
\rho(r)=\rho_{0} e^{-b(\ln r)^{2}}
$$

All the above-mentioned models will be tested by using observed data in this research.

For a long time, the models of urban population density were empirical models rather than theoretical models. If and only if a model is derivable from general principles, it will lead us to its underlying rationale. During the 1970s, Clark's model was theoretically derived from a utility-maximizing model by assuming a unitary value of the price elasticity of housing services $[49,50]$. Another attempt is to derive the Clark model by means of the entropy-maximizing method. Based on spatial interaction models for traffic distribution, a negative exponential decay model was derived by Bussiere and Snickars [51]. The process was regarded as an indirect derivation of Clark's model through the entropy-maximization idea [1]. By postulating the urban cell system, Chen derived Clark's model gracefully by means of the entropy-maximizing principle [7]. The direct derivation of Chen [7] is simpler and clearer than that of Bussiere and Snickars [51]. Entropy-maximization suggests the best balance between the equity of individuals and the efficiency of the whole [52]. Entropy-maximization may be associated with the urban sustainable development of cities [37].

\subsection{Study Area and Data}

In this part, we first present a brief overview of the study area, Hangzhou Municipality. We then explain the method to deal with the census data, and the data with which we conduct our research. Hangzhou, as the capital of Zhejiang Province in the east of China, is famous for its scenic beauty. In 2000, the city-region of Hangzhou included a mostly urbanized municipality and rural region. The urban municipality comprises six districts, i.e., qu, including Shangcheng, Xiacheng, Jianggan, Gongshu, Xihu, and Binjiang, and the rural region consists of seven counties, that is, xian, including Xiaoshan, Yuhang, Fuyang, Linan, Tonglu, Jiande and Chunan, under its administration. From 2000 to 2019, Xiaoshan, Yuhang, Fuyang and Linan also became districts from counties under the control of the government. Considering that the main body of urbanized region in Hangzhou is still made up of the six districts in 2000, which is called Hangzhou Municipality, including Shangcheng, Xiacheng, Jianggan, Gongshu, Xihu, and Binjiang, we take Hangzhou Municipality as the study area. Hangzhou Municipality includes the urban core (Figure 1), including Shangcheng and Xiacheng, and the inner suburb, including Jianggan, Gongshu, Xihu, and Binjiang. The outer suburbs include Xiaoshan, Yuhang, Fuyang, Linan, Tonglu, Jiande and Chunan [53]. 


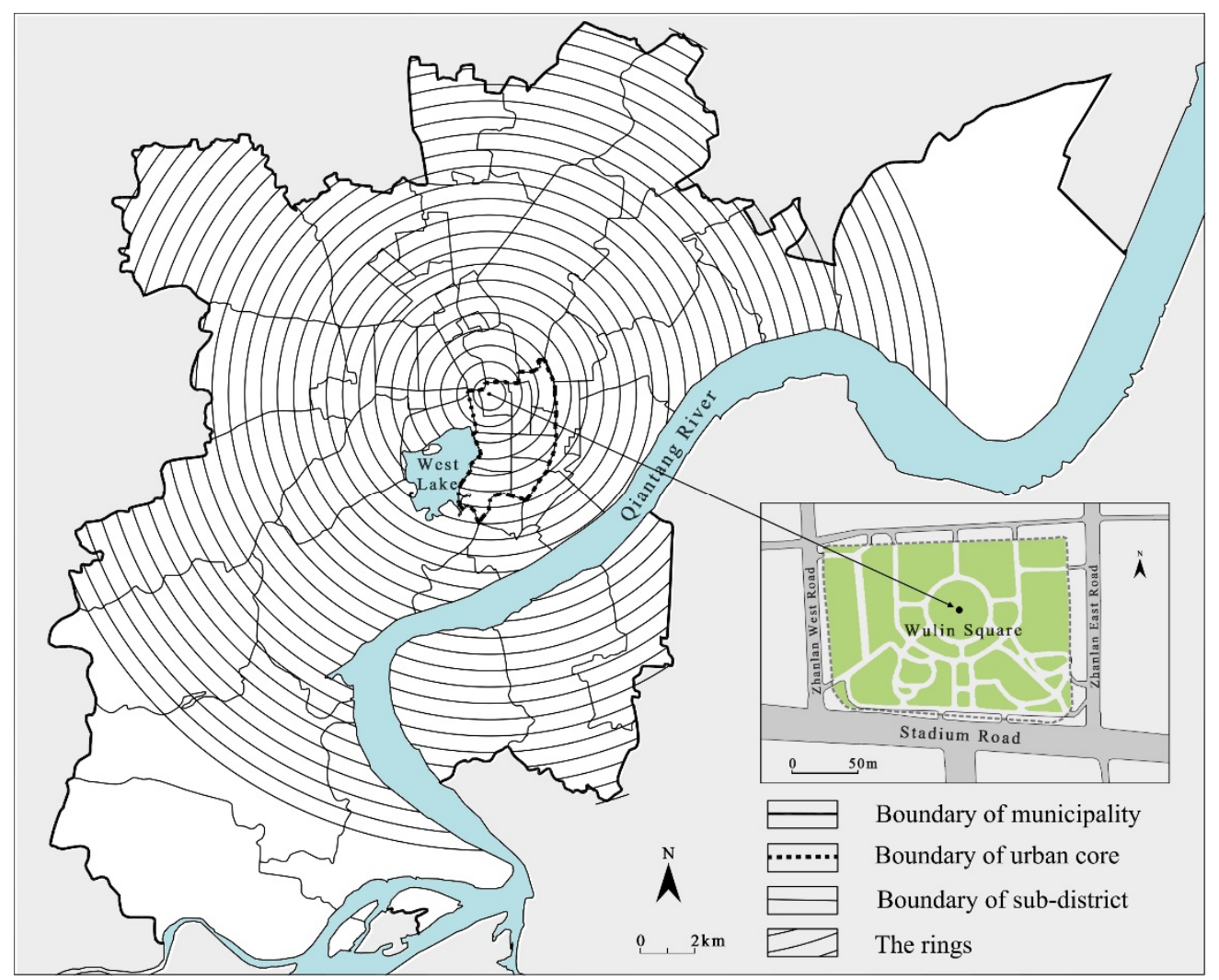

Figure 1. A map of the zonal system indicating sub-districts of Hangzhou and the corresponding system of concentric circles. Note: For urbanized area, a sub-district is termed jiedao in Chinese, and for rural area, sub-district is termed Xiang and Zhen.

In 1964 (the second census), 1982 (the third census), 1990 (the fourth census), 2000 (the fifth census) and 2010 (the sixth census), the municipality contained a population of 1071.0, 1348.1, 1647.5, 2451.1 and 3560.4 thousand respectively. According to the area of Hangzhou Municipality in 2000, the population density in each year was 1516.4, 1908.8, 2332.6, and 3470.5 and 5041.1 persons per square kilometer (later abbreviated as $\mathrm{p} / \mathrm{km}^{2}$ ) respectively. From 1964 to 2010, the administrative divisions of the Hangzhou sub-district level (jiedao, zhen, xiang) have changed, which makes it difficult to compare the data before and after a certain period. For the convenience of research, some sub-districts are merged, which is called the sub-district unit. The municipality of Hangzhou was composed of 44 sub-district units in 1964 and 1982, 47 ones in 1990, 50 ones in 2000 and 44 ones in 2010. A sub-district unit is an irregular small zone, which form a zonal system of Hangzhou (Figure 1). For the convenience of research, we use the map of 2000 to process the data of 2010, on the basis of making clear the changes of administrative divisions by sub-district in the period 2000-2010. Hangzhou was the capital of China in ancient times, especially in the South Song Dynasty. In modern times, Hangzhou is one of the important cities in the Yangtze Delta and has a close relationship with Shanghai. Therefore Hangzhou will provide a good case for empirical studies of population densities in urban China.

\subsection{Data Processing Methodology}

The firsthand data come from the second, third, fourth, fifth and sixth censuses in 1964, 1982, 1990, 2000, and 2010, respectively. In order to study urban growth and the spatio-temporal evolution of the urban geographic system, the data of population by subdistrict are transformed into those by spatial distribution. The data are dealt with according to the following four steps. (1) Adjust the boundaries of each sub-district according to historical materials and records. We obtain the map with spatial boundaries of sub-districts of Hangzhou in the four years from various sources of local governments and numerous 
field trips. To get the population of sub-districts whose boundaries are definite, some sub-districts are merged, according to the changes of the boundaries of sub-districts in 1964-2010. (2) Calculate the population density of each sub-district in the five years (i.e., 1964, 1982, 1990, 2000, and 2010). The boundaries of sub-districts form a zonal system of each year [1]. From the map of zonal systems, we can obtain the data of the area of each sub-district in the five years. At last, the data of population density of each subdistrict in the five years are calculated according to the sub-district population and area. (3) Determine the city center of Hangzhou. The central location is identified as Wulin Square. The main bases are as follows: (a) The busiest area (esp. that of business and trade) of the city is located around Wulin Square, and as a result, some scholars think it is the "old CBD (Central Business District)" of Hangzhou [54-56], because, since 2001, Hangzhou has built a modern CBD in Qianjiang New Town on the North Bank of Qiantang River. There is no doubt that the newly built CBD (Qianjiang new town) cannot become the urban center of Hangzhou, no matter from the geographical location or from the actual function; (b) The population densities of several sub-districts near Wulin Square are of the highest level constantly within several decades; (c) Wulin Square was regarded as the center of modern and contemporary activities of Hangzhou city [54]; and (d) Wulin Square is the centroid of Hangzhou municipality. So the center of Wulin Square is regarded as the approximating position of city center of Hangzhou. (4) Compute the average population density by rings. That is to say, the population density based on zonal systems is turned into that based on concentric circles.

The spatial series of urban population density in Hangzhou are the results of the spatially weighted average. The methods of transforming zone-based population density data in irregular sub-districts into ring-based population density data in regular circular banded zones should be explained. The process of data extraction are as follows (see supplementary materials).

Step 1: calculate the population density of each sub-district. Suppose there are $n$ sub-districts in Hangzhou in a given year. The sub-districts can be numbered as $j=1,2,3$, $\ldots, n$. If the population size and area of the $j$-th sub-district are $P_{j}$ and $A_{j}$, respectively, then the population density is

$$
\rho_{j}=\frac{P_{j}}{A_{j}} .
$$

This step is very simple can be realized by MS Excel.

Step 2: define circular ring zones. Taking the center of Wulin Square as the center of circles and $l_{i}$ as radiuses, we can draw a series of concentric circles. The difference of radius is $\Delta l=l_{i+1}-l_{i}=0.6$. Two adjacent circles form a circular ring zone. The radius of the $i$ th circular ring zone can be expressed as

$$
l_{i}=0.6(i-1 / 2)
$$

where $I=0,2, \ldots, 26$ (unit: $\mathrm{km}$ ). The first circle is actually a point, and $i=0$ represents the city center point. Thus the main part of Hangzhou municipality are divided into 26 circular ring zones (see Figure 1).

Step 3: compute the intersectional areas of circular ring zones and administrative sub-districts. As indicated above, a sub-district is an irregular small region, while a circular ring zone is a regular banded region. If two adjacent circles cut a sub-district, there will be an intersectional area between the corresponding regular ring zone and the irregular sub-district. For the $i$-th circular zone and the $j$-th sub-district, the intersectional area can be expressed as:

$$
S_{i j}=\rho_{j} \cap\left(0.6^{2} \pi\left((i+1)^{2}-i^{2}\right)\right)
$$

where $S_{i j}$ denotes the intersectional area, and $\cap$ means to take the intersection of two sets $\left(i=1,2, \ldots, 26 ; j=1,2, \ldots, n ; 0 \leq S_{i j} \leq S_{j}\right)$. This step is the most complicated one, which can be realized with the help of Arc GIS technology. 
Step 4: defining population density weights. The intersectional areas of the $i$-th circular ring zone and the $n$ sub-districts can serve as spatial weights for circular density computation. The formula is

$$
W_{i j}=S_{i j} / \sum_{j=1}^{n} S_{i j}
$$

where $W_{i j}$ denotes spatial weight for average population density.

Step 5: calculate the average density of circular ring zones. The average population density of the $i$ th circular ring zone can be calculated by the following formula

$$
\rho_{i}=\sum_{j=1}^{n} W_{i j} \rho_{j}
$$

where $\rho_{i}$ is the average population density of the $i$ th circular ring zone. Using the aboveillustrated method, step by step, we worked out the average population density datasets of Hangzhou in 1964, 1982, 1990, 2000 and 2010 (Table 1). As a supplement, the data of sub-district population density is also used to analyze the spatial restructuring of the population.

\begin{tabular}{|c|c|c|c|c|c|c|}
\hline \multirow{2}{*}{$\begin{array}{l}\text { The Order of Rings } \\
\text { (i) }\end{array}$} & \multirow{2}{*}{$\begin{array}{l}\text { Distance } \\
\text { (km) }\end{array}$} & \multicolumn{5}{|c|}{ Population Density $\left(\mathrm{p} / \mathrm{km}^{2}\right)$} \\
\hline & & 1964 & 1982 & 1990 & 2000 & 2010 \\
\hline 1 & 0.3 & 24,131 & 29,540 & 29,928 & 28,184 & 26,635 \\
\hline 2 & 0.9 & 18,966 & 22,225 & 26,634 & 26,821 & 25,419 \\
\hline 3 & 1.5 & 16,282 & 18,957 & 22,262 & 24,621 & 22,702 \\
\hline 4 & 2.1 & 16,007 & 19,232 & 21,612 & 23,176 & 20,923 \\
\hline 5 & 2.7 & 13,052 & 15,439 & 17,290 & 18,910 & 19,466 \\
\hline 6 & 3.3 & 8252 & 9929 & 12,478 & 16,911 & 18,830 \\
\hline 7 & 3.9 & 5798 & 7026 & 9896 & 14,522 & 16,594 \\
\hline 8 & 4.5 & 2626 & 3461 & 5560 & 10,829 & 12,428 \\
\hline 9 & 5.1 & 2143 & 2807 & 4180 & 7282 & 9226 \\
\hline 10 & 5.7 & 2142 & 2689 & 3923 & 6200 & 7996 \\
\hline 11 & 6.3 & 2185 & 2566 & 3516 & 5644 & 7363 \\
\hline 12 & 6.9 & 1438 & 1693 & 2197 & 4297 & 6487 \\
\hline 13 & 7.5 & 1083 & 1371 & 1796 & 3806 & 5863 \\
\hline 14 & 8.1 & 967 & 1256 & 1634 & 3153 & 5260 \\
\hline 15 & 8.7 & 842 & 1114 & 1442 & 2683 & 4830 \\
\hline 16 & 9.3 & 848 & 973 & 1265 & 2354 & 4509 \\
\hline 17 & 9.9 & 818 & 1051 & 1163 & 2028 & 4200 \\
\hline 18 & 10.5 & 812 & 1051 & 1143 & 1828 & 4062 \\
\hline 19 & 11.1 & 807 & 1051 & 1160 & 1651 & 3846 \\
\hline 20 & 11.7 & 625 & 979 & 1093 & 1581 & 3788 \\
\hline 21 & 12.3 & 691 & 901 & 1006 & 1490 & 3673 \\
\hline 22 & 12.9 & 575 & 870 & 972 & 1465 & 3543 \\
\hline 23 & 13.5 & 532 & 666 & 817 & 1278 & 2953 \\
\hline 24 & 14.1 & 381 & 487 & 679 & 1033 & 2630 \\
\hline 25 & 14.7 & 369 & 489 & 582 & 958 & 2351 \\
\hline 26 & 15.3 & 375 & 456 & 563 & 882 & 2125 \\
\hline
\end{tabular}

Table 1. Datasets of urban population density and distance by ring zones in Hangzhou in 1964, 1982, 1990, 2000 , and 2010.

\section{Empirical Results}

\subsection{Modeling Population Densities in Hangzhou}

Mathematical modeling is a good approach to deep researching urban form and growth. The mathematical expression of a model reflects the macro-structure of a city, while the parameter values of the model reflect the dynamic characteristics of the microelements of the city. In scientific research, mathematical models can be classified into two categories: mechanism models and parametric models [57]. Accordingly, there exist 
two methods for establishing mathematical models: analytical method and experimental method [58]. This paper is devoted to making parametric models of urban growth and form based on population density distribution by using the experimental method. The modeling process of the experiment method for parameter models is to select one or two most possible functions from a set of possible functions by comparison and analysis. The main points of modeling Hangzhou's population density can be outlined as follows: (1) Parameter character. The model must bear two basic parameters: one is the proportionality coefficient indicative of central density (initial value), and the other is the characteristic scale parameter indicating the density decay rate (characteristic value). (2) Distance-decay principle. Urban density follows distance-decay law in geography. (3) Feasible functions. The models can be chosen from the family of distance functions. (4) Model selection. The better functions can be found to describe the urban population density of Hangzhou by fitting the possible models to observational data. (5) Calibration and verification. The numerical experiment, statistical analysis, and comparison method can be employed to test and improve models' expressions. The key points are tabulated to make the idea and process of model building clearer (Table 2). In addition, the ideas from the analytical method for mechanism models can be used to make a complement judgment.

Table 2. The summary process of parametric modeling of the urban density of Hangzhou.

\begin{tabular}{ccc}
\hline Item & Content & Explanation \\
\hline Purpose & Modeling & $\begin{array}{c}\text { Find proper functions to model urban } \\
\text { population density of Hangzhou }\end{array}$ \\
\hline Logical basis & Distance-decay effect & $\begin{array}{c}\text { Urban population density gradually } \\
\text { decreases from the urban center to } \\
\text { the suburbs }\end{array}$ \\
\hline Available functions & Distance function & $\begin{array}{c}\text { Linear function, logarithmic function, } \\
\text { exponential function, power function, } \\
\text { quadratic exponential function, lognormal } \\
\text { function, gamma function, etc. }\end{array}$ \\
\hline Experiment & Test and improvement & $\begin{array}{c}\text { Use numerical, statistical, and comparative } \\
\text { analyses to test and calibrate models }\end{array}$ \\
\hline Function & Models' role & $\begin{array}{c}\text { (1) Predict urban growth; (2) explain urban } \\
\text { evolution; (3) sharpen urban questions }\end{array}$ \\
\hline
\end{tabular}

The functions discussed in the preceding section can be fitted to the data of the average population densities in 1964, 1982, 1990, 2000 and 2010. The method of parameter estimation is the ordinary least square (OLS) regression. With the help of $r-D(r)$ scatterplots, we can select the possible models. We test four simple functions, including linear, exponential, logarithmic and power, and three more complicated functions, including lognormal, power-exponential and quadratic exponential. The expression of each function and the result of regressions are listed in Tables 3 and 4. Apparently, using the data of average urban population density brings good results of the regression. For example, with the exception of the linear model, all the coefficient determinations $R^{2}$ of the other models are above 0.8 , with most of them above 0.9 . 
Table 3. The parameter estimation results of the models population densities in Hangzhou (1964-2010).

\begin{tabular}{|c|c|c|c|c|c|c|}
\hline Year & Type of Model & Expression of Model & $a$ & $b$ & $R^{2}$ & $F$ \\
\hline \multirow{6}{*}{1964} & Linear & $\rho(r)=a-b r$ & $14,019.571$ & 1192.114 & 0.631 & 41.000 \\
\hline & Exponential & $\rho(r)=a \exp (-b r)$ & $16,429.413$ & 0.281 & 0.907 & 234.169 \\
\hline & Logarithmic & $\rho(r)=a-b \ln r$ & $16,799.930$ & 6860.880 & 0.909 & 240.407 \\
\hline & Power & $\rho(r)=a r^{-b}$ & $19,116.626$ & 1.329 & 0.886 & 186.192 \\
\hline & Lognormal & $\rho(r)=a \exp \left(-b(\ln r)^{2}\right)$ & $16,430.129$ & 0.550 & 0.920 & 276.889 \\
\hline & Power-exponential & $\left.\rho(r)=a \exp \left(-b r^{\sigma}\right)\right)$ & $85,622.987$ & 1.535 & 0.958 & 546.829 \\
\hline \multirow{6}{*}{1982} & Linear & $\rho(r)=a-b r$ & $16,781.830$ & 1420.395 & 0.630 & 40.901 \\
\hline & Exponential & $\rho(r)=a \exp (-b r)$ & $19,493.085$ & 0.272 & 0.904 & 225.927 \\
\hline & Logarithmic & $\rho(r)=a-b \ln r$ & $20,143.212$ & 8202.296 & 0.915 & 256.917 \\
\hline & Power & $\rho(r)=a r^{-b}$ & $22,712.030$ & 1.294 & 0.887 & 188.962 \\
\hline & Lognormal & $\rho(r)=a \exp \left(-b(\ln r)^{2}\right)$ & $19,455.030$ & 0.533 & 0.915 & 259.698 \\
\hline & Power-exponential & $\left.\rho(r)=a \exp \left(-b r^{\sigma}\right)\right)$ & $113,984.359$ & 1.637 & 0.957 & 527.971 \\
\hline \multirow{6}{*}{1990} & Linear & $\rho(r)=a-b r$ & $19,408.637$ & 1626.398 & 0.681 & 51.262 \\
\hline & Exponential & $\rho(r)=a \exp (-b r)$ & $24,583.475$ & 0.275 & 0.931 & 323.755 \\
\hline & Logarithmic & $\rho(r)=a-b \ln r$ & $22,658.850$ & 9051.841 & 0.918 & 269.276 \\
\hline & Power & $\rho(r)=a r^{-b}$ & $27,182.362$ & 1.274 & 0.872 & 162.981 \\
\hline & Lognormal & $\rho(r)=a \exp \left(-b(\ln r)^{2}\right)$ & $24,618.028$ & 0.539 & 0.946 & 418.267 \\
\hline & Power-exponential & $\left.\rho(r)=a \exp \left(-b r^{\sigma}\right)\right)$ & $80,862.588$ & 1.140 & 0.966 & 687.942 \\
\hline \multirow{6}{*}{2000} & Linear & $\rho(r)=a-b r$ & $21,927.176$ & 1757.632 & 0.784 & 87.323 \\
\hline & Exponential & $\rho(r)=a \exp (-b r)$ & $30,786.603$ & 0.250 & 0.972 & 826.901 \\
\hline & Logarithmic & $\rho(r)=a-b \ln r$ & $24,239.823$ & 9100.723 & 0.915 & 259.055 \\
\hline & Power & $\rho(r)=a r^{-b}$ & $30,760.150$ & 1.108 & 0.829 & 116.691 \\
\hline & Lognormal & $\rho(r)=a \exp \left(-b(\ln r)^{2}\right)$ & $30,588.663$ & 0.489 & 0.979 & 1140.566 \\
\hline & Power-exponential & $\left.\rho(r)=a \exp \left(-b r^{\sigma}\right)\right)$ & $47,053.952$ & 0.523 & 0.981 & 1226.034 \\
\hline \multirow{6}{*}{2010} & Linear & $\rho(r)=a-b r$ & $21,785.021$ & 1571.545 & 0.824 & 112.309 \\
\hline & Exponential & $\rho(r)=a \exp (-b r)$ & $26,447.238$ & 0.172 & 0.960 & 583.084 \\
\hline & Logarithmic & $\rho(r)=a-b \ln r$ & $23,501.138$ & 7937.438 & 0.915 & 257.357 \\
\hline & Power & $\rho(r)=a r^{-b}$ & $26,900.863$ & 0.770 & 0.841 & 127.359 \\
\hline & Lognormal & $\rho(r)=a \exp \left(-b(\ln r)^{2}\right)$ & $26,296.234$ & 0.335 & 0.966 & 683.762 \\
\hline & Power-exponential & $\left.\rho(r)=a \exp \left(-b r^{\sigma}\right)\right)$ & $39,012.813$ & 0.430 & 0.974 & 906.916 \\
\hline
\end{tabular}

Notes: In this paper, all parameter estimates are based on 14 decimal places, but only 3 decimal places are shown. In the power-exponential model, the restraint parameter, that is, latent scaling exponent, $\sigma$, equals to 0.475 in 1964, 0.450 in 1982, 0.550 in 1990 , 0.756 in 2000 , and 0.699 in 2010, respectively.

Table 4. The regression results for a quadratic exponential model of population density in Hangzhou (1964-2010).

\begin{tabular}{cccc}
\hline Year & Quadratic Exponential Model & Transformed by Logarithm & $\boldsymbol{R}^{\mathbf{2}}$ \\
\hline 1964 & $\rho(r)=35,383.469 e^{-0.576 r+0.019 r^{2}}$ & $\ln \rho(r)=10.474-0.576 r+0.019 r^{2}$ & 0.974 \\
1982 & $\rho(r)=41,150.856 e^{-0.560 r+0.018 r^{2}}$ & $\ln \rho(r)=10.625-0.560 r+0.018 r^{2}$ & 0.971 \\
1990 & $\rho(r)=47,120.711 e^{-0.525 r+0.016 r^{2}}$ & $\ln \rho(r)=10.760-0.525 r+0.016 r^{2}$ & 0.982 \\
2000 & $\rho(r)=42,744.508 e^{-0.376 r+0.008 r^{2}}$ & $\ln \rho(r)=10.663-0.376 r+0.008 r^{2}$ & 0.988 \\
2010 & $\rho(r)=34,031.936 e^{-0.269 r+0.006 r^{2}}$ & $\ln \rho(r)=10.435-0.269 r+0.006 r^{2}$ & 0.981 \\
\hline
\end{tabular}


The parameter estimation results suggest possible models for Hangzhou's population density distribution. As far as the four simple functions are concerned, it is easy to exclude the linear model with the worst goodness of fit, according to the results of regressions (Table 3). Generally, speaking, urban population density distribution follows the distance decay law. The linear function is not one of the alternative models of distance decay patterns in geography $[36,59,60]$. The goodness of fit of the exponential one is a bit worse than that of the logarithmic one in 1964 and 1982, while the former is better than the latter since 1990, especially in 2000 and 2010. So totally speaking, Clark's model occupies a dominant position in modeling population densities of Hangzhou in the 1990s. In particular, the exponential model bears a good theoretical basis in describing urban population density distribution [7,51]. It is not difficult to find that the power model (Smeed's model) does not dominate in the analysis of Hangzhou's population density. As a result, it is apparent that the density distribution of the urban population is not fractal. The results of the lognormal model and that of the power-exponential model are often close to one another, but the lognormal model has not enough theoretical basis. Although the lognormal model can be fitted better to the observational data in some years, it cannot be the total tendency. The coefficient of determination $\left(R^{2}\right)$ is an important basis for model selection, but not the only one [61]. When we extend the curve of the quadratic exponential model fitted by Hangzhou's data to some position in the suburban area, population density increases again and reaches a certain value which is much higher than that in the urban center. This phenomenon can be treated as overfitting [62]. The result is absurd, for it does not accord with reality, so this model is excluded. In fact, there is an essential distinction in the model structure between Newling's model and the quadratic exponential models regressed by the data of Hangzhou. In Newling's model, the coefficient of first-order term is positive, and that of quadratic order term is negative, while in the quadratic exponential models regressed by Hangzhou's data in the five years, the coefficients of first-order term are negative, and those of quadratic order term are positive. The difference in model structure shows that we can't get a model like that of Newling, and that there isn't any crater and the tidal wave of expansion in the evolution of the spatial distribution of population density in Hangzhou within the past several decades. The difference in model structure also decides the above-mentioned absurd result.

It is difficult to choose a mathematical model for complex systems. Only through comprehensive analysis can we choose the appropriate mathematical expressions. Albeit the goodness of fit of the quadratic exponential model, we also exclude it (see Table 4 and Appendix A). Compared with the four simple models, the lognormal model and the power-exponential model are more careful ones. As a result, the goodness of fit of the two complicated functions is better than the four simple ones. Except for 1990, the power-exponential model has better goodness of fit to Hangzhou's population density than the lognormal model. Based on the above analyses, two models can be employed to analyze Hangzhou's population density distribution. One is Clark's negative exponential model, and the other is the power-exponential model. The latter is the generalized result of the former. Clark's model can be derived by using the principle of entropy maximization. Its theoretical rationale is clear [1,7]. According to the ideas from the analytical method for mechanistic models, we select Clark's model to describe the expected form of urban population density. On the other hand, the power-exponential model shows a good effect of fitting to the population distribution of Hangzhou. In terms of the ideas from the experimental method for parameter models, we choose this model to depict the real form of Hangzhou population density. In fact, geography is involved in two worlds: real-world and the ideal world [63]. Clark's model is mainly suitable for the urban density in the ideal world, while the power-exponential model is more suitable for the urban density in the real world. The values of the hidden scaling exponent of the power-exponential model, $\sigma$, reflect the deviation degree of the real state of urban population density distribution to the ideal state that is based on entropy maximization. 


\subsection{Urban Growth Reflected by Model Parameters}

The changes of some parameters in the urban density models may indicate the features of urban growth in Hangzhou for about half a century since 1964. First of all, the parameter $\sigma$ of the power-exponential model reflects the tendency of changes of information entropy of urban geographic system essentially. Entropy is an important measure for spatial analysis of Hangzhou's urban growth. In fact, entropy theory is very effective in theoretical and empirical studies of geographical systems [64-67]. In order to make it clear, we estimate the information entropy of the spatial distribution of the population in Hangzhou city. The core, inner suburb and outer suburb constitute the three big zones of Hangzhou city (See Appendix B). The population of each city zone is displayed in Table 5. The proportion of each zone's population to city total can be regarded as the probability of spatial distribution of the population. So we can use Shannon's formula of Shannon entropy to estimate the information entropy of population distribution in Hangzhou. The formula is as below:

$$
H=-\sum_{i=1}^{N} p_{i} \log _{2} p_{i}
$$

where $H$ refers to Shannon's information entropy, $p_{i}$ denotes the probability of zone $i$ $(i=1,2,3), N=3$ is the number of spatial units. It is easy to find that the information entropy of Hangzhou's population distribution of the three big zone keeps increasing but slightly fluctuates, indicating that the urban geographic system of Hangzhou is becoming more complex and orderly than ever. Moreover, the changes of information entropy are consistent with those of parameter $\sigma$ of the power-exponential model, because there is a linear relationship between them, that is, $\sigma=3.106 H-2.833\left(R^{2}=0.980\right)$. So the changes of parameter $\sigma$ reflect the tendency of changes of information entropy of the urban geographic system.

Table 5. Changes of some parameters of the density models and information entropy of Hangzhou's urban system.

\begin{tabular}{|c|c|c|c|c|c|}
\hline Item & 1964 & 1982 & 1990 & 2000 & 2010 \\
\hline Gradient of the negative exponential model & 0.281 & 0.272 & 0.275 & 0.250 & 0.172 \\
\hline Characteristic radius $r_{0}(\mathrm{~km})$ & 3.564 & 3.671 & 3.641 & 3.996 & 5.824 \\
\hline Latent scaling exponent $\sigma$ of the power-exponential model & 0.475 & 0.450 & 0.550 & 0.756 & 0.699 \\
\hline Characteristic radius $r_{0}^{*}(\mathrm{~km})$ & 1.946 & 1.971 & 2.339 & 3.414 & 5.580 \\
\hline Gap between two characteristic radii $\Delta r(\mathrm{~km})$ & 1.619 & 1.700 & 1.302 & 0.582 & 0.244 \\
\hline Population of Hangzhou's core (person) & 430,302 & 462,390 & 407,536 & 341,633 & 298,162 \\
\hline Population of Hangzhou's inner suburb (person) & 640,705 & 885,754 & 1239,930 & $2,109,453$ & $3,262,229$ \\
\hline Population of Hangzhou's outer suburb (person) & 3146,324 & $3,912,328$ & $4,184,668$ & $4,426,893$ & $5,139,982$ \\
\hline Population of Hangzhou's total city (person) & $4,217,331$ & $5,260,472$ & $5,832,134$ & $6,877,979$ & $8,700,373$ \\
\hline Information entropy of population distribution of Hangzhou (bit) & 1.064 & 1.059 & 1.087 & 1.147 & 1.146 \\
\hline
\end{tabular}

Note: The first characteristic radius, $r_{0}$, is based on Clark's model, which reflects the ideal state of population density decay. The second characteristic radius, $r_{0}^{*}$, is based on the power-exponential model, which reflects the real state of population density distribution.

The entropy-maximizing defined at the macro level is consistent with the utilitymaximizing defined at the micro-level. In fact, scholars finished the demonstration that disaggregate models of individual resource allocation in space based on utilitymaximizing were consistent with models of spatial interaction based on ideas from entropymaximizing [68]. Entropy-maximizing is a goal or a kind of tendency in the evolution of the self-organizing system, while the information entropy of the urban geographic system, in reality, may not be but can tend to be the maximum. From this point of view, the tendency of the change of parameter $\sigma$ in the power-exponential model reflects the optimization in the process of self-organizing evolution of each function unit of Hangzhou. For Hangzhou city, the latent scaling exponent $\sigma$ in the power-exponential model fluctuates, increases and approaches 1, namely, from 0.475 in 1964, to 0.450 in 1982, to 0.550 in 1990, 0.756 in 2000, and then to 0.699 in 2010. Correspondingly, the spatial information entropy values 
are $1.064,1.059,1.087,1.147$, and 1.146 bit in these years. The latent scaling exponent is a highly positive linear correlation to the spatial information entropy. This suggests that the power-exponential distribution of urban population density evolves into the ideal Clark model with the lapse of time. The parameter values and its change suggests a constrained entropy-maximizing process of Hangzhou's urban evolution.

Next, we may analyze the features of urban growth in Hangzhou by some parameters in Clark's model. Clark's law is the ideal form of the power-exponential model and some analytical functions of the latter can be realized directly by the former. Moreover, Clark's model also describes Hangzhou's population density well. In the negative exponential model, parameter $a$ refers to the theoretic population density of the city center, and the absolute value of the parameter $b$ represents the gradient of population density decay. Figure 2 provides us the comparison of the gradients in Hangzhou in 1964, 1982, 1990, 2000, and 2010. Totally speaking, the fact tells us that the gradient tends to flatten but fluctuates with the lapse of time, for the gradient declined from 0.281 in 1964 to 0.272 in 1982, and slightly rose to 0.275 in 1990, and then declined to 0.250 in 2000, and 0.172 in 2010. The gradient coefficient is a linear negative correlation to the spatial information entropy. The change of the gradients before the 1990s is inappreciable, while that after the 1990s is distinct, especially in 2000s. In Figure 2a, the three lines in 1964, 1982 and 1990 are almost parallel, while the lines in 2000 and 2010 slopes more gently than the former three ones, indicating that the gradient of population density became flatter than ever since the 1990s. As far as population densities in the city center are concerned, its theoretical values increased from $16,429 \mathrm{p} / \mathrm{km}^{2}$ in 1964 , to $19,493 \mathrm{p} / \mathrm{km}^{2}$ in 1982 , to $24,583 \mathrm{p} / \mathrm{km}^{2}$ in 1990 , to $30,787 \mathrm{p} / \mathrm{km}^{2}$ in 2000 , and then $26,447 \mathrm{p} / \mathrm{km}^{2}$ in 2010 . Its actual values increased first, and then began to decline during the period from 1990 to $2010\left(24,131 \mathrm{p} / \mathrm{km}^{2}\right.$ in 1964 , $29,540 \mathrm{p} / \mathrm{km}^{2}$ in $1982,29,928 \mathrm{p} / \mathrm{km}^{2}$ in $1990,28,184 \mathrm{p} / \mathrm{km}^{2}$ in 2000 , and $26,635 \mathrm{p} / \mathrm{km}^{2}$ in 2010). Therefore, the actual value of population density in the center of the city has been declining since 2000, but the theoretical value has been declining since 2010. Obviously, the decline time of the theoretical value is later than that of the actual value. In Figure $2 b$, the line in 2010 not only becomes flatter than that in 2000, but also the highest value of the line in 2010 is lower than that in 2010, which is a reflection of the model structure. In sum, the changes of parameters in the power-exponential model and the negative exponential model reflect some characteristics of urban growth in Hangzhou in the period from 1964 to 2010. They are closely related to the development of the urban economy and the concentration and decentralization of the population. The explanation will be given in the following section.

The spatial feature of urban population density distribution can be reflected by characteristic radius. Both Clark's model and the power-exponential model can give the estimated value of the urban characteristic radius of population distribution. Where Clark's model is concerned, the reciprocal of the density gradient is just the characteristic radius of urban population distribution [7], and the formula is

$$
r_{0}=\frac{1}{b}
$$

Using this formula, we can easily calculate the characteristic radius of Hangzhou's population distribution: $3.564 \mathrm{~km}$ in $1964,3.671 \mathrm{~km}$ in $1982,3.641 \mathrm{~km}$ in 1990, $3.996 \mathrm{~km}$ in 2000, and 5.824 in 2010. Clark's model reflects the ideal state of urban population density distribution, thus $r_{0}$ can be treated as the ideal or expected characteristic radius. Based on the power-exponential model, the characteristic radius can be estimated by the following relation [37]

$$
r_{0}^{*}=\left(\frac{1}{\sigma b}\right)^{1 / \sigma} .
$$




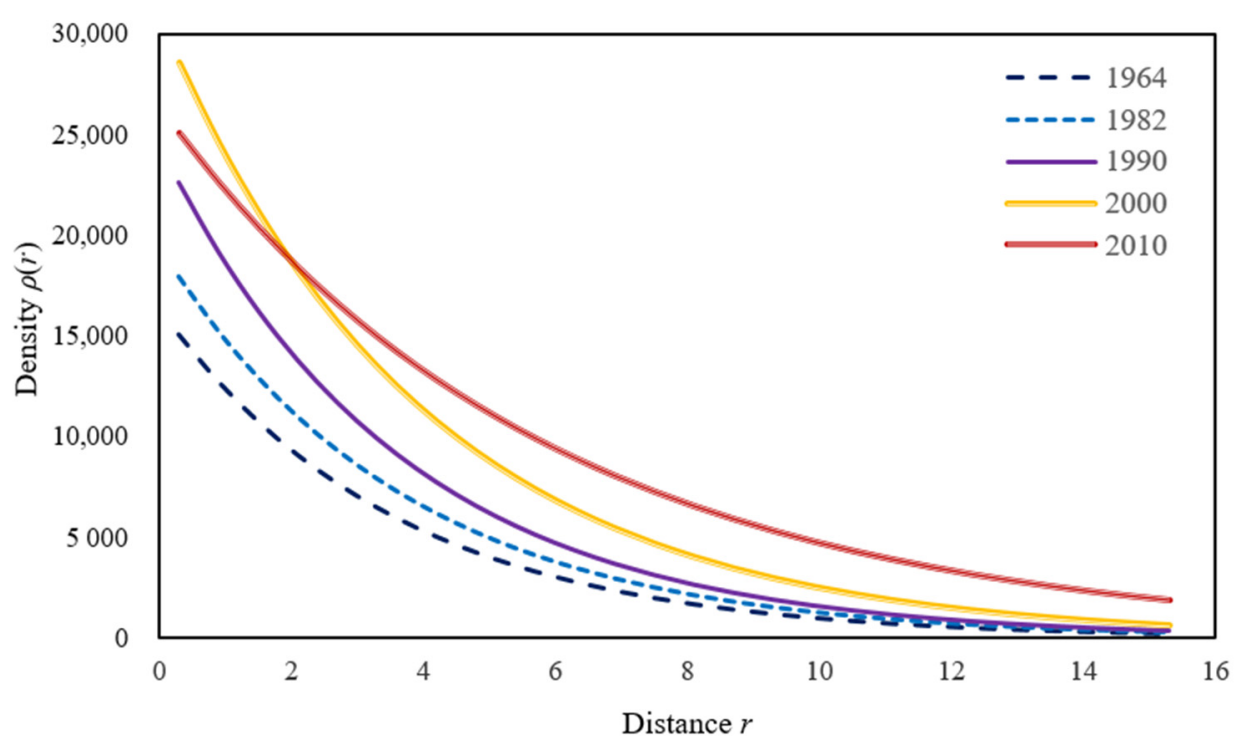

(a)

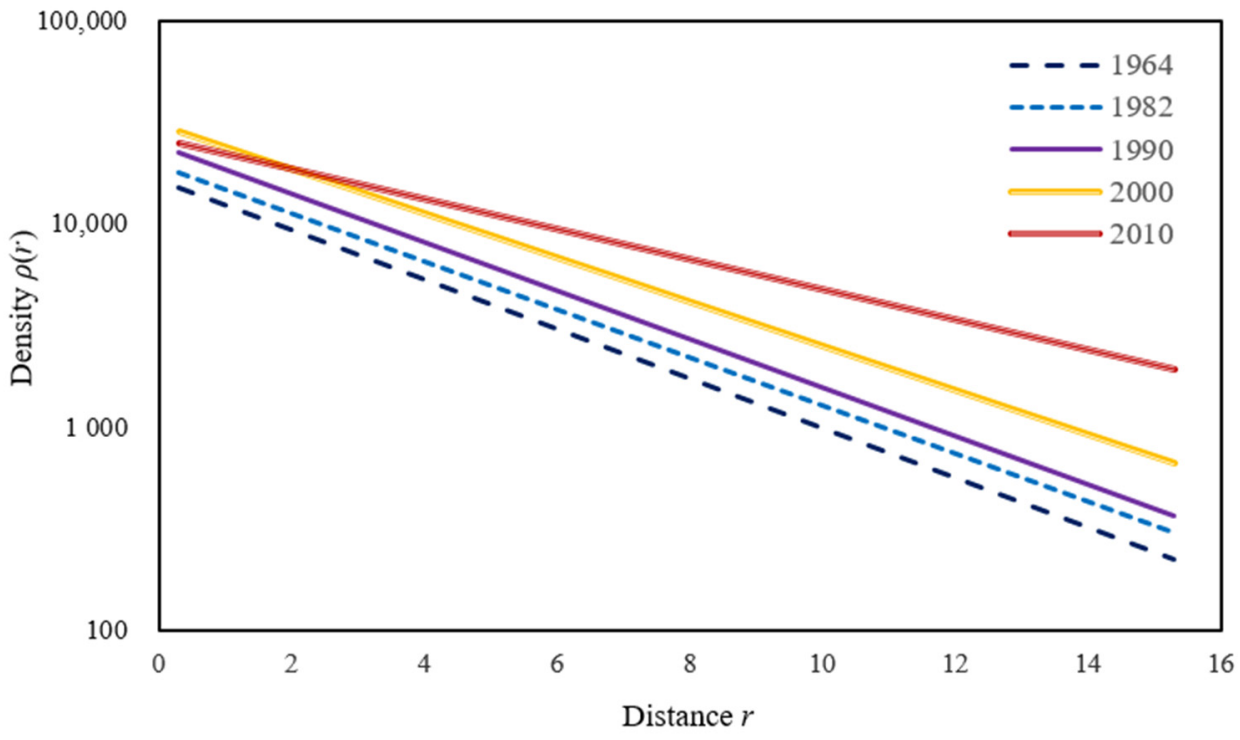

(b)

Figure 2. Comparing the gradients of population density decay in Hangzhou in different years (1964-2010). (a) Plot of urban density decay; (b) Semi-log plot for urban density decay.

By means of this formula, we can calculate another type of characteristic radius of Hangzhou's population distribution: $1.946 \mathrm{~km}$ in 1964, $1.971 \mathrm{~km}$ in 1982, $2.339 \mathrm{~km}$ in 1990, $3.414 \mathrm{~km}$ in 2000, and 5.580 in 2010. The power-exponential model reflects the real state of urban population density distribution, thus $r_{0}^{*}$ can be regarded as the actual characteristic radius. Urban characteristic radius reflects the average distance of activities of urban residents, and it depends on the development of technology and means of transportation. The difference between the two characteristic radii can be computed by

$$
\Delta r=r_{0}-r_{0}^{*}=\frac{1}{b}-\left(\frac{1}{\sigma b}\right)^{1 / \sigma},
$$

where it reflects the gap between the real state and ideal state of urban population density distribution. The gaps in different years are as follows: $1.619 \mathrm{~km}$ in $1964,1.700 \mathrm{~km}$ in $1982,1.302 \mathrm{~km}$ in $1990,0.787 \mathrm{~km}$ in 2000 , and 0.752 in 2010 . It can be seen that with the development of the city of Hangzhou, the actual characteristic radius is closer and closer 
to the expected characteristic radius. Hangzhou city development has the trend of spatial optimization by self-organization.

\subsection{The Spatial Restructuring of Population in Hangzhou}

Now, it is necessary to discuss the spatial restructuring of the population in Hangzhou city by analyzing zonal datasets. The data analysis based on the zonal system consisting of sub-districts with irregular shape differs from that based on the concentric ring system with regular shape. Data analysis based on concentric circles can reflect the global statistical law and the core-periphery relationship of urban growth, while the data analysis based on sub-districts can mirror the local variation feature of spatial distribution. Comparing the figures of the spatial distribution of population density by sub-district in Hangzhou in 1964, $1982,1990,2000$, and 2010, we can find that the tendency of concentration of population is weakened (Figure 3). On the one hand, the number of the largest population density of the sub-district decreased from $62,596 \mathrm{p} / \mathrm{km}^{2}$ in 1964 , to $57,977 \mathrm{p} / \mathrm{km}^{2}$ in 1982 , to $47,369 \mathrm{p} / \mathrm{km}^{2}$ in 1990 , to $33,707 \mathrm{p} / \mathrm{km}^{2}$ in 2000 and then to $46,738 \mathrm{p} / \mathrm{km}^{2}$ in 2010 ; on the other hand, the number of the sub-districts with a population density more than $10,000 \mathrm{p} / \mathrm{km}^{2}$ increased, and the extent of such sub-districts was enlarged, for example, in 1964 and 1982 most of them were distributed within $4.8 \mathrm{~km}$ from the city center, while in 1990, 2000 and 2010 most of them were distributed within $6.2 \mathrm{~km}$ from the city center.

The spatial reconstruction of a city can be mirrored by the spatio-temporal variation of population density. The spatial distribution of the growth rate of population density in 1964-1982, 1982-1990, 1990-2000 and 2000-2010 shows that there are four stages in the process of spatial restructuring of the population in Hangzhou in about half a century since 1964 (Figure 4). In the first stage, the rural population increased, and then the population in the core area grew slowly. In the second stage, the population in the core area began to decline, and the population in the inner suburb began to concentrate and increase clarity. In the third stage, the population of the core area decreased fast, while that of the inner suburban area increased rapidly. In the fourth stage, the population of the core area continued to decrease, while that of the inner suburb kept increase. In fact, there were two forces in the spatial restructuring of the population in Hangzhou. One is the centrifugal force resulting from the decentralization of the population in the core, and the other is the centripetal force resulting from the centralization of the population [53]. The changes of sub-district population density tell us that suburbanization in Hangzhou occurred in 1982-1990 and accelerated in the 1990s and in the 2000s, and that the period of 1964-1982 may be the prelude of decentralization of population.

The features of urban growth can be reflected in two aspects. One is the relationship between the growth rate of population densities and the distance from the city center, and the other is the relationship between the growth rate of population densities and densities of the former year in a certain period. The growth rate of population density was limited in the period 1964-1982, while in the period 1982-1990, 1990-2000 and 2000-2010 was larger. For example, the largest growth rate of population density in 1964-1982, 1982-1990, $1990-2000$ and $2000-2010$ was $112.8 \%, 717.7 \%, 449.3 \%$ and $388.9 \%$, respectively. For another example, as far as the proportion of the sub-districts with growth rate over 100 percent to total sub-districts is concerned, it was 6.3 percent, $12.5 \%, 23.5 \%$ and $22.2 \%$ in $1964-1982$, 1982-1990, 1990-2000 and 2000-2010, respectively. Compared with population density in 1964-1982, more and more sub-districts within the distance of $5 \mathrm{~km}$ from the city center began to lessen density in 1982-1990, 1990-2000 and 2000-2010, while sub-districts with the distance of 5 to $12 \mathrm{~km}$ from the city center gained more and more density especially in the period 1990-2000 and 2000-2010, and some sub-districts with the distance of 12 to $20 \mathrm{~km}$ from the city center gained density clearly in the period 2000-2010 (Figure 4a). On the other hand, it can be found that the sub-districts with larger growth of population density were concentrated in the position of lower population density especially less than $5000 \mathrm{p} / \mathrm{km}^{2}$. Compared with that in the period 1964-1982, some of the sub-districts with a population density less than $5000 \mathrm{p} / \mathrm{km}^{2}$ gained more density in the period 1982-1990, 1990-2000 and 
2000-2010 (Figure 4b). In the countryside, many sub-districts of the ones with a population density more than $25,000 \mathrm{p} / \mathrm{km}^{2}$ lost their densities in the period 1982-1990, 1990-2000 and 2000-2010.

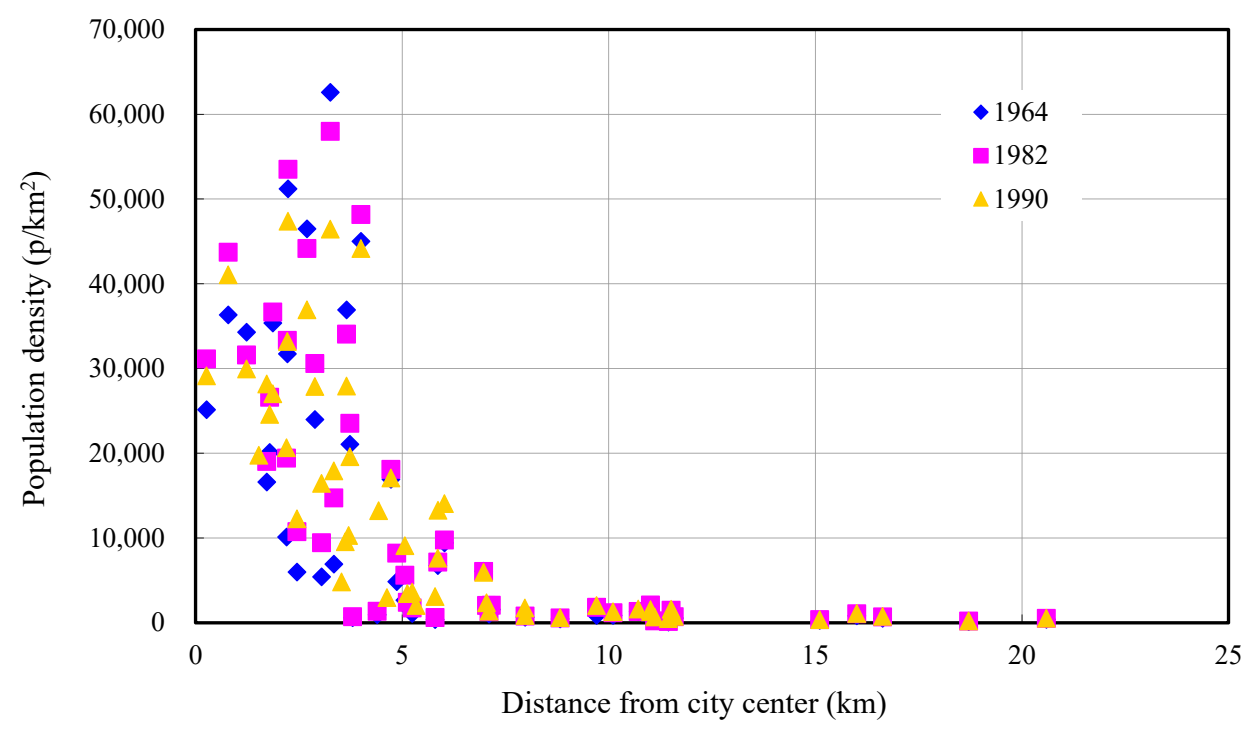

(a)

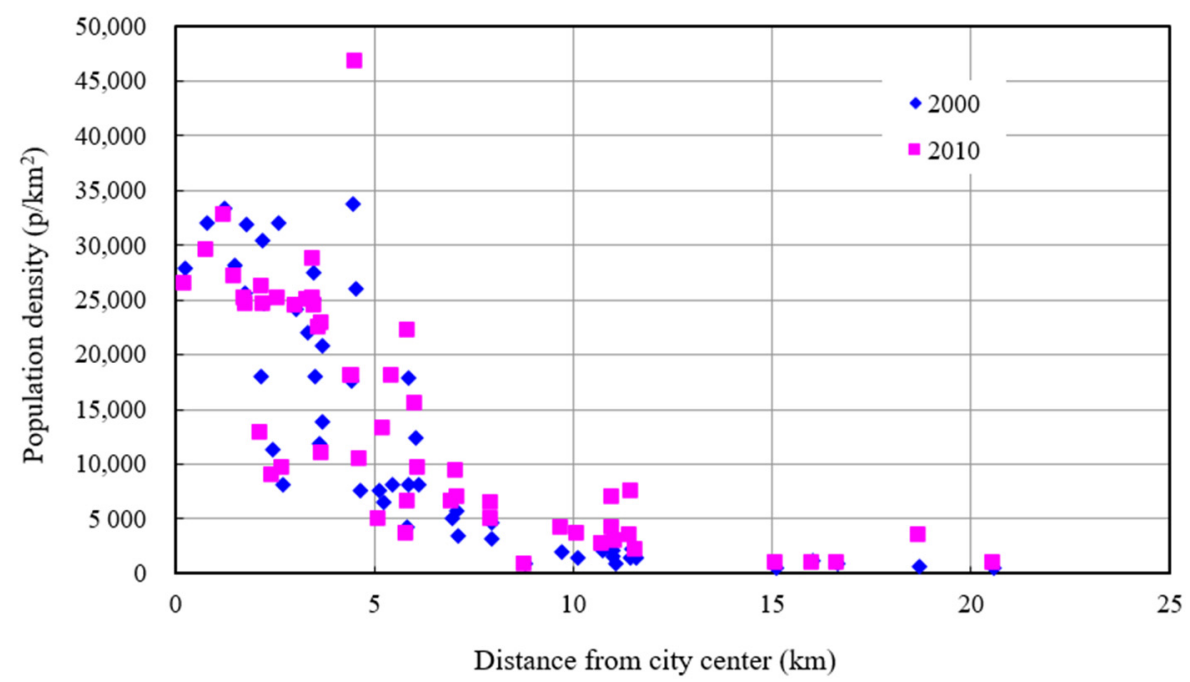

(b)

Figure 3. Population density by sub-district vs. distance from the city center in Hangzhou (1964, 1982, 1990, 2000 and 2010). (a) Population density vs. distance from the city center in 1964, 1982, and 1990; (b) Population density vs. distance from the city center in 2000 and 2010. Source: Data from Hangzhou's Census Office. The data materials are as follows: (1) Manually Tabulated Data of the Second Population Census of Hangzhou, 1964; (2) Manually Tabulated Data of the Second Population Census of Hangzhou, 1982; (3) Manually Tabulated Data of the Second Population Census of Hangzhou, 1990; (4) Manually Tabulated Data of the Second Population Census of Hangzhou, 2000; (5) Manually Tabulated Data of the Second Population Census of Hangzhou, 2010. 


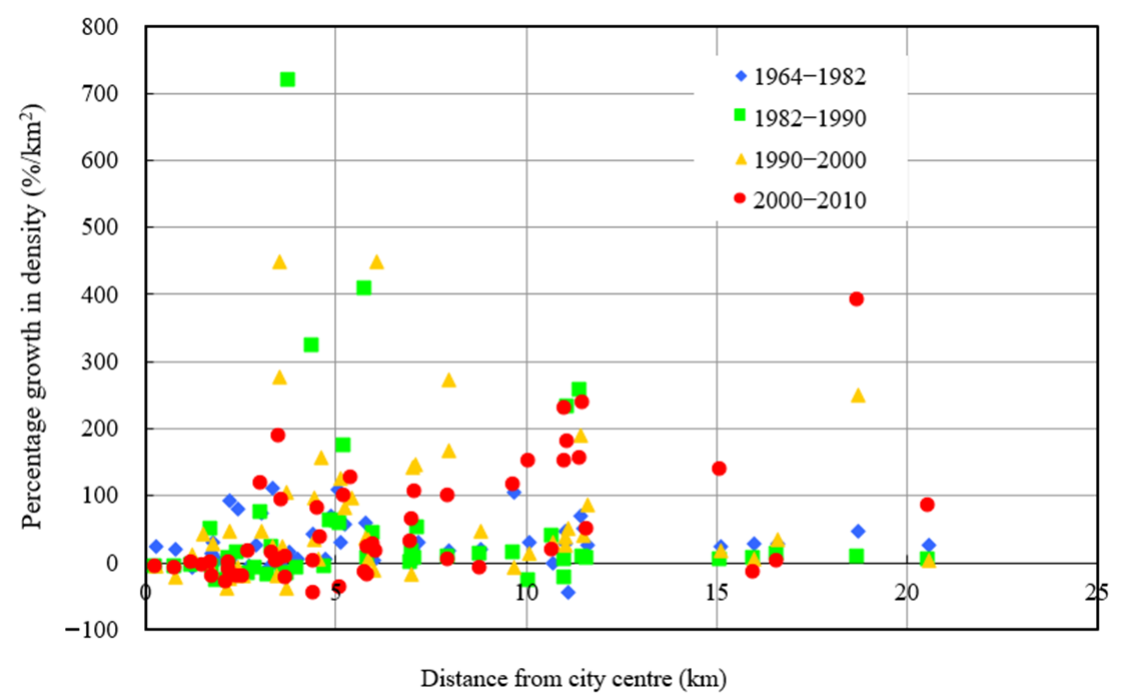

(a)

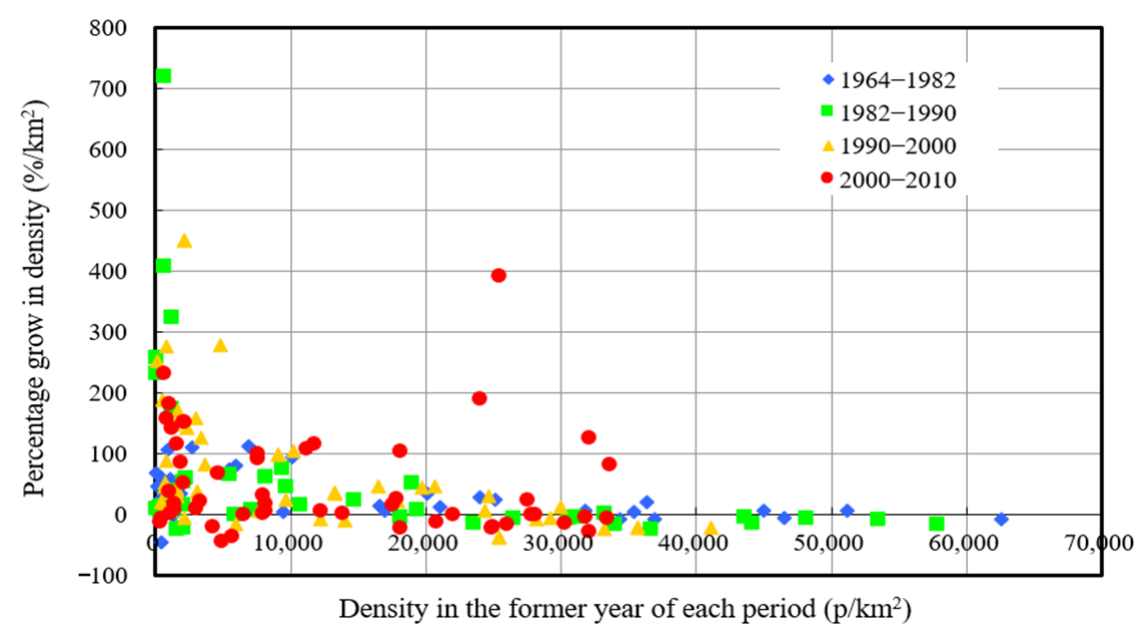

(b)

Figure 4. Restructuring of population density in Hangzhou (1964-1982, 1982-1990, 1990-2000 and 2000-2010). (a) The percentage growth in population density vs. the distance from the city center; (b) The percentage growth in population density vs. density in the former year of each period. Source: Data from Hangzhou's Census Office (1964, 1982, 1990, 2000 and 2010).

In Figure 3a,b, as far as the sub-districts in 1964, 1982, 1990, 2000 and 2010 are concerned, no matter they are near or far from the city center, and no matter the area of these sub-districts (i.e., patches on the map) is large or small, the absolute value of population density is reflected in the figures. Basically, it can be seen that the sub-districts with the highest population density are not in the place of the city center, but in the places that are a certain distance from the city center, and not too far away from it. The change in the percentage of population density in the sub-districts (Figure $4 \mathrm{~b}$ ) reflects the growth of the population living at different distances from the city center, which can reflect the actual development of the region in Hangzhou. For example, the suburbanization of the central area makes the population density of the sub-districts in the central area negative growth, and the real estate development near the inner suburbs makes the population of buying houses in this area increase greatly, which leads to the growth of population density of sub-districts in this area. It is worth pointing out that there are differences in 
the growth of population density in different periods. For example, during the period 1990-2000, the sub-districts with obvious population growth mainly concentrated in the inner part of the inner suburb, while during the period 2000-2010, this situation changed, and the sub-districts with obvious population growth evolved into the outer part of the inner suburb, which indicates that after 2000, the suburbanization of Hangzhou continued and has gone further. This phenomenon indicates the spatial re-organizing process of decentralization and concentration of urban population in different regions. As we know, population density is inversely related to the distance from the city center. For example, sub-districts in the core with a shorter distance from the city center reduced their densities in the 1980s, the 1990s and the 2000s, indicating they played important roles in population decentralization. For another example, some sub-districts in the outer part of the inner suburb with longer distance from the city center, increase more densities in the 1990s and the 2000s, indicating that such areas played important roles in population concentration.

\subsection{Suburbanization Accounts for the Spatial Restructuring of Population}

The spatial restructuring process of urban population is a spatial dynamics of population migration. Suburbanization is closely related to the changes in urban internal spatial structure in Hangzhou [53]. The modeling results show that the gradient in the negative exponential function of Hangzhou tended to be flatter, especially since the 1990s. The actual values of the population density of the city center declined. The above facts should be attributed to the development of suburbanization. Suburbanization is associated with the dynamics of increasing information entropy of population distribution in Hangzhou. It is suburbanization and decentralization that weakened the difference of population distribution between the core and its periphery. It should be pointed out that suburbanization in Hangzhou was still at an incipient stage before 2000. As a result, the theoretical value of population density of the city center in Clark's model still keeps increasing. However, it decreased in the period 2000-2010, indicating that suburbanization in Hangzhou in the new century has entered a new stage of development, which is like what happens in the Western cities.

The causes of Hangzhou's suburbanization are summarized as follows:

(1) The development of transportation facilities and fast growth of automobiles. Since the 1980s, the performance of the reformation and opening-up policy changed the way of investment and construction of Hangzhou's traffic from state monopoly to the multi investment system. The former was based on the traditional planned economy, and the latter was based on a joint venture and commodity economy. The construction of urban traffic improves the relationship between the urban core and the suburbs. For example, the first subway in Hangzhou was put into use in 2012, and so far five metro lines have been constructed. Most of these subway lines play the role of effectively connecting the central area and the suburbs, facilitating the long-distance commuting of citizens, and effectively promoting the suburbanization of residence. The fast-growing of automobiles also propelled the development of suburbanization in Hangzhou since the 1990s. For example, the number of automobiles increased by 908 thousand from 170 thousand in 1996 to 1078 thousand in 2005, with a growth rate of $532.9 \%$ and the annual growth rate of $22.8 \%$ [69,70]. The private automobile came into urban families in Hangzhou so that some of the driving forces of suburbanization are similar to the Western cities.

(2) The renovation of the core and the construction of new residential quarters in suburbs. The large scale renovation of the old city began in Hangzhou in the early 1980s. In 1986, the government of Hangzhou put forward that urban development should combine the renovation of the old city with the construction of new quarters in suburbs. In the period from 1986 to the first half-year of 1999, as the result of rehabilitation, houses totaling 8.75 million sq $\mathrm{m}$ living space were demolished, and 110,000 households and work units (Danwei) had to move away from the core. In the course of the renovation of the core, most of the households whose homes were demolished were 
relocated to the suburbs. At the same time, about 130 new residential quarters, which are attractive to urban residents because of their attractive environments, facilities, and cheap prices, were constructed in the inner suburb [53]. Accordingly, residential suburbanization was promoted.

(3) The reform of urban land use system and the spatial pattern of land and housing price. In the planned economy, urban land values in China were not evaluated and the land was charged with a small fixed rate $[8,10]$. Since the year 1992, with the establishment of the system of paid urban land use, the market of urban land and real estate have been developing in Hangzhou. This change of urban land use system brought the shift of land use in the core from industrial to commercial and other tertiary uses [71]. In order to reduce the cost and obtain more space, more and more factories and their employees moved out of the core to the suburbs. Development of the land market acted on the spatial patterns of the prices of land and housing in Hangzhou, which decay from the core to the peripheral area. This pattern of housing prices guides the development of suburbanization and decentralization of the population. With the fast growth of housing prices, more and more housing purchasers choose housing in suburbs in order to save money or to buy more space with the same money.

\subsection{The Changes of Economic System and Urban Growth}

The information entropy of Hangzhou's population distribution in 1964-2010 kept increasing but fluctuated. This indicates that the urban geographic system of Hangzhou is becoming more complex and orderly than ever, albeit the information entropy decreased in the period 1964-1982. Since the 1980s, the policy of reformation and opening-up and the establishment of a market economy exerted tremendous influences on urban growth and the spatio-temporal structure of Hangzhou's population density. The policy of reformation and opening-up made the city of Hangzhou become an opening system, while the establishment of a market economy strengthened the ability of Hangzhou's urban system as self-organization. Although parts of self-organization are not in order, the whole of it can evolve into a highly ordered structure. It is no doubt that the performance of the reformation and opening-up policy and the transformation from a planned economy to a market one all increased the ability of Hangzhou city as a self-organizing system. Order emerges from instability and from random growth spurts [72,73]. In a word, self-organizing evolution strengthened the spatial complexity of Hangzhou city, and raised the utilities of Hangzhou's function units. In this way, the total tendency of the changes of information entropy or the parameter $\sigma$ of the power-exponential model in Hangzhou since the 1980s can be explained.

The economic system may also have something to do with the goodness of fit of Clark's model to urban density data. As we know, the negative exponential function was demonstrated to describe population densities in the Western cities successfully. It is also applicable to Chinese cities with a market economy or socialist market economy [8-10]. However, till now it has not been proved whether Clark's model is applicable to Chinese cities with the early planned economy especially before the 1980s. In Hangzhou, the fact that the goodness of fit of the negative exponential function was worse than that of the logarithmic function in 1964 and 1982 can be attributed to the early planned economy.

Both the value of information entropy and the parameter $\sigma$ of the power-exponential model declined during the period from 1964 to 1982 . This may be associated with the disorder of urban construction and development in the period of the Cultural Revolution (1966 to 1976). Urbanization during the Culture Revolution was marked by negative sentiments of anti-urbanism and the attendant program of rusticating urban youths, which was a unique episode in China's urban development [71]. In the period, the Three-Line (Sanxian) Construction entered its peak, with factories transferred from cities to the mountainous areas and distributed dispersedly [36]. Totally speaking, the Culture Revolution sent urban China in a state of disorder. The properties include anarchism prevailing, investment of urban construction declining, urban planning being abandoned, and lack of urban infras- 
tructure and slower development or degradation of the urban economy. In Hangzhou, the fact that information entropy of population distribution declined in the period 1964-1982 means the chaos of urban development in the period of the Cultural Revolution.

\section{Discussion}

The empirical analytical results show that, based on the statistical average processing of spatial data, Hangzhou's population density can be modeled by two functions. One is a negative exponential function, and the other is a power-exponential function. The former is termed Clark's model in literature [1,5], and the latter is the generalized results from Clark's model and Sharratt's model [37]. The model is different from the truth. The result of the mathematical modeling of a complex system is not unique. Different types of models have different uses in scientific research. As indicated above, geography has two worlds: real-world and ideal world [63]. On the other hand, system research falls into three categories: behavioral research, values research, and normative research [74]. Clark's model is derivable from the entropy maximization principle, indicating the system optimization process [1,7]. Therefore, Clark's model can be used to model the ideal state of Hangzhou's population distribution for normative research. In contrast, the power-exponential model can be used to model the real state of Hangzhou's population distribution for behavioral research, that is, empirical studies (Table 6). The latent scaling exponent values reflect the extent of deviation of real state to the optimized state of urban population distribution. The gap between the real state and the ideal state is just a problem to be solved by city planning and design. For system analysis, the gap between the goal and the status quo is the problem to be solved $[57,75]$. By comparing the differences between the characteristic radius based on Clark's model and that based on the power-exponential model, we can judge the distance between the real state and expected state of urban population distribution. The above analysis shows that, based on a good social and economic environment, a city will automatically tend to the optimal state through the self-organization process. It lends further support to the viewpoint that geographical laws of urban systems are the law of evolution rather than that of existence [76].

Table 6. Comparison of two models of Hangzhou's urban population density distribution.

\begin{tabular}{cccccc}
\hline $\begin{array}{c}\text { Geographical } \\
\text { World }\end{array}$ & Research Type & Model & Model Type & Modeling Method & Parameter \\
\hline Real world & $\begin{array}{c}\text { Behavioral } \\
\text { research }\end{array}$ & $\begin{array}{c}\text { Power-exponential } \\
\text { model }\end{array}$ & Parameter model & Analytical and & $\begin{array}{c}\text { Real characteristic } \\
\text { radius } r_{0} \text { and latent } \\
\text { scaling exponent } \sigma\end{array}$ \\
Ideal world & $\begin{array}{c}\text { Normative } \\
\text { research }\end{array}$ & $\begin{array}{c}\text { Negative model } \\
\text { (Clark's model) }\end{array}$ & Mechanism model & Experimental model & $\begin{array}{c}\text { Ideal characteristic } \\
\text { radius } r_{0}^{*}\end{array}$ \\
\hline
\end{tabular}

Note: Clark's model is originally a parameter model based on empirical analyses. After it was derived from the principle of entropy maximization, the model had become a mechanism model with clear theoretical meaning.

By mathematical modeling and empirical analysis, we obtained new insight into Hangzhou's development from 1964 to 2010. The spatio-temporal evolution of Hangzhou has different influencing factors and realistic characteristics at different stages (Table 7). Before 1982, the driving force of urban development was the simple top-down force based on command economics, while after 1982, the dual force based on both the topdown government management and bottom-up market economics influence urban growth. New changes of both external environment and internal factor in Hangzhou after 1982 include the development of transportation facilities and fast-growing of automobiles, the renovation of the core and the construction of new residential quarters in suburbs, and the reform of urban land use system and the spatial pattern of land and housing price. The resultant of forces of these changes derived suburbanization and decentralization of population in the city. From 2000 to 2010, real estate and city-building movement began to 
affect urban development. In particular, real estate has left a significant mark on the urban population distribution of Hangzhou.

Table 7. Internal and external factors affecting the evolution of urban population distribution in Hangzhou in different stages.

\begin{tabular}{|c|c|c|}
\hline Stage & External Environment & Internal Factor \\
\hline 1964-1982 & $\begin{array}{l}\text { Political movement (Cultural Revolution); } \\
\text { planned economy; Lack of urban planning; The } \\
\text { background of unit society (Danwei) }\end{array}$ & $\begin{array}{l}\text { Large scale construction of unit communities in the background } \\
\text { of the system of unit society; The residential area of the unit } \\
\text { built in a centralized way; Decentralized distribution of } \\
\text { urban industry }\end{array}$ \\
\hline 1982-1990 & $\begin{array}{l}\text { Reform and opening-up policy; After the } \\
\text { reform and opening up, begin to work out the } \\
\text { urban master plan for the first time and play a } \\
\text { guiding role in urban construction and } \\
\text { development; Urban development following } \\
\text { the idea of centripetal agglomeration }\end{array}$ & $\begin{array}{l}\text { The relocation of residents caused by the transformation of the } \\
\text { urban center and the old city under the guidance of the } \\
\text { government; Residents forced to move due to the construction } \\
\text { of transportation facilities; Under the effect of the land price } \\
\text { difference between urban and rural areas, some industries } \\
\text { began to move out }\end{array}$ \\
\hline 1990-2000 & $\begin{array}{l}\text { Reform and opening-up policy, socialist market } \\
\text { economy; Establishment of the system of paid } \\
\text { use of land; Reform of housing system; The } \\
\text { idea of urban development is gradually } \\
\text { changing from the idea of agglomeration to } \\
\text { that of centrifugal diffusion }\end{array}$ & $\begin{array}{c}\text { The construction of a large number of bus lines has improved } \\
\text { the connection between urban and rural areas; A large number } \\
\text { of high-speed highway construction; A large number of } \\
\text { industrial enterprises move out; The development of private } \\
\text { cars; The construction of suburban affordable housing } \\
\text { community; Construction of suburban residential area; } \\
\text { Construction of villas in suburbs; The rise of suburban } \\
\text { shopping centers }\end{array}$ \\
\hline 2000-2010 & $\begin{array}{l}\text { Market economy, real estate development; } \\
\text { Implementation of the policy of invigorating } \\
\text { the city through industry; The development } \\
\text { concept changing from the West Lake era to the } \\
\text { Qiantang River Era; Implementation of new } \\
\text { town construction policy; Implementation of } \\
\text { Development Zone Construction Policy }\end{array}$ & $\begin{array}{l}\text { The rapid development of private cars; Large scale construction } \\
\text { of residential areas in suburbs; Suburban shopping centers at all } \\
\text { levels were popularized; In 2007, the subway began planning } \\
\text { and construction and put into use five years later; Active } \\
\text { suburbanization to improve living area and living environment; } \\
\text { the rise and development of suburban development zone cause } \\
\text { the employment suburbanization }\end{array}$ \\
\hline
\end{tabular}

This research makes contributions to the literature in the following aspects. Firstly, it provides empirical research on population densities in another important Chinese city, Hangzhou, the ancient capital of China. As the above-mentioned, less research on population density is undertaken in China. As for the reasons, one is that data are less plentiful and less reliable in developing countries, and the other is that the scarcity of public accessible research data on China is evident because of the country's longtime concern of national security and reluctance of releasing data to the public [10,77]. Moreover, an important reason comes from the frequent adjustment of administrative divisions by Chinese local government, who often ignore providing convenience for comparative research of one district or sub-district in a different year. For example, the geographical database of China's census, called sub-district, often changes over time. As a result, clarifying the evolution of the boundaries of sub-districts and deal with sub-district data should be important tasks in studying urban growth and population densities in China. Fieldwork was carried out in Hangzhou to obtain unpublished data of the population of sub-districts and to ascertain the spatial boundaries of the sub-districts in Hangzhou from 1964 to 2010. Secondly, it tries to indicate the development characters of urban population densities in China in the late stage of reform and opening up (1990-2000) and the ten years in the new century. It is important to note that the previous literature on population densities in China used data from the third (in 1982) and the fourth (in 1990) censuses. Therefore, we do not know much about that in the 1990s and the 2000s. Only because data from the fifth census (in 2000) and the sixth census (in 2010) became available has such a study been possible. Thirdly and most important of all, it tries to prescribe the feature of urban growth and the spatial restructuring of the population in Hangzhou in a long period from 1964 to 2010. In the past half a century before 2010, China's urbanization experienced complex changes, caused 
by multiplex driving forces. The driving forces include socialist planned economy in the period 1960-1965 and the period of the 1980s, the Cultural Revolution (1966-1976) marked by an unprecedented political movement and retrogression of the economy in the nation's history [71], and socialist market economy or transitional market economy in the 1990s and 2000s.

Unlike the West where urban population density has attracted a great deal of geographers' attention, research on population density distribution in urban China is still scarce although since the end of the 1990s some research progress has been made. This research provides the literature with an interesting case on population densities in another important socialist city, Hangzhou, ancient capital of China. Moreover and most important of all, modeling urban population densities also provides us an effective tool to indicate the features of urban growth and spatial restructuring of population. The chief shortcomings of this study are as follows. Firstly, due to the lack of necessary spatial data, the distribution and evolution of urban population density after 2010 are not analyzed. As mentioned above, the pattern of administrative divisions in China has been constantly adjusted. The zonal system of sub-districts in Hangzhou city change continuously. Only by obtaining both the change map of Hangzhou Street (sub-districts) boundary and the data of the seventh census (2020), can we transform it into the data of urban population density distribution and make analyses for recent years' change. Secondly, limited to the length of the paper, there is no computer simulation of the urban evolution mechanism. Computer simulation technology can make up for the lack of experiment in urban research, and help us to deeply analyze the mechanism of urban development [3,78-80]. The work will be carried out in the future.

\section{Conclusions}

An urban study should proceed first by describing how an urban phenomenon and its parts work and then understanding why. The description depends on mathematics and measurement, and understanding relies heavily on observation, experience, artificially constructed experiments, and computer simulation. The premise of understanding is an effective description, while performance is a convincing explanation. The main work of this paper lies in two aspects: describing the population density distribution of Hangzhou city and explain its antecedents and consequences.

One is the description of urban growth by modeling population density distribution. Seven functions are tested with the data of Hangzhou in 1964, 1982, 1990, 2000, and 2010, respectively. The result shows that the negative exponential function and the powerexponential one occupy significant positions in modeling the population densities of Hangzhou. In fact, these two functions have a close relationship with each other, for the former is the ideal form of the latter. With the aid of the changes of some parameters in the regressive models, we try to analyze the features of urban growth in Hangzhou in about half a century before 2010. The change of the parameter $\sigma$ in the power-exponential function reflects the tendency of change of information entropy of the urban geographic system in Hangzhou. The parameter values kept increasing but fluctuated, indicating that the features of urban growth characterized by information entropy-maximizing and self-organizing. In the period 1964-1982, the information entropy decreased showing degradation of urban economy and construction in Hangzhou, which should be attributed to the Culture Revolution (1966-1976). Since the 1980s, the policy of reformation and opening-up and the establishment of a market economy exerted tremendous influences on urban growth. Reformation and opening-up made Hangzhou become an opening system, and the market economy strengthened the ability of Hangzhou's urban system as self-organization, which is behavior from below to top.

The other is the explanation of urban evolution in Hangzhou by analyzing growing factors. The changes in the gradient in the negative exponential function of Hangzhou have something to do with the concentration and decentralization of the population. In the past half a century before 2010, the process of spatial restructuring of the population 
in Hangzhou can be divided into three stages. The features of the three stages are as follows: (1) population development in the rural area and progressively slower increase of population in the core in the first stage; (2) population decline in the core and population concentration in a part of the inner suburb in the second stage; and (3) fast population decline in the core and fast population concentration in the inner suburb in the third stage. The gradient becoming flattered in 2000 and 2010 is closely related to the development of suburbanization and decentralization of the population in Hangzhou. It is also noticed that Hangzhou's suburbanization was still at an incipient stage before 2000, for the theoretical value of population density of the city center in Clark's model still keeps increasing although its actual value declined in the 1990s. However, it decreased in the period 2000-2010, indicating that suburbanization in Hangzhou in the new century has entered a new stage of development, which is like what happens in the Western cities. Hangzhou's suburbanization and decentralization of population have their causes, including the development of transportation facilities and fast-growing of automobiles, the renovation of the core and the construction of new residential quarters in suburbs, and the reform of urban land use system and the spatial pattern of land and housing price. In a word, both internal and external factors affect the evolution of urban population distribution in Hangzhou in different stages.

Supplementary Materials: The following are available online at https:/ /www.mdpi.com/2071-1 050/13/2/463/s1. Spatial data transformed from sub-district-based density to circular ring-based density. In this MS Excel file, we show the processes and results of transforming the population density data based on irregular sub-districts to the spatial series data based on regular circular ring zones in different years.

Author Contributions: Conceptualization, J.F. and Y.C.; methodology, J.F. and Y.C.; software, J.F.; validation, J.F. and Y.C.; formal analysis, J.F.; investigation, J.F.; resources, J.F.; data curation, J.F.; writing—original draft preparation, J.F.; writing—review and editing, Y.C.; visualization, J.F.; supervision, Y.C.; project administration, J.F.; funding acquisition, J.F. and Y.C. Both authors have read and agreed to the published version of the manuscript.

Funding: This research was funded by the National Natural Science Foundations of China, grant numbers 41671157 and 41671167.

Institutional Review Board Statement: Not applicable (This study does not involve humans or animals).

Informed Consent Statement: Informed consent was obtained from all subjects involved in the study.

Data Availability Statement: The data are availability in the Supplementary Materials.

Acknowledgments: Many thanks to the two anonymous reviewers whose constructive comments were helpful in improving the quality of this paper.

Conflicts of Interest: The authors declare no conflict of interest. The funders had no role in the design of the study; in the collection, analyses, or interpretation of data; in the writing of the manuscript, or in the decision to publish the results.

\section{Appendix A. Fitting Newling's Model to the Data of Urban Population Density of Hangzhou}

Newling's model is a quadratic exponential function. The mathematical expression can be found in Table 3. The model indicates that with the increase of independent variable r, dependent variable $\rho(r)$ declines rapidly, then declines slowly, and increases after the nadir. For the case in 2000 , the result is:

$$
\rho(r)=42,744.508 e^{-0.376 r+0.008 r^{2}} .
$$

From its picture, we can see that $\rho(r)$ declines first, begins to increase slowly when $r=23.5 \mathrm{~km}$, and increases rapidly after $r=35 \mathrm{~km}$. When $r=50 \mathrm{~km}, \rho(r)$ is 4.5 times as many 
as the population density at the city center. So, as far as the spatial distribution of urban population density is concerned, the model is impossible.

\section{Appendix B. The Spatial Concept of Hangzhou City}

In China, Lao-cheng-qu (old urban region) is a concept comparable to that of the central city in Western cities, and it will be referred to as Hangzhou's core. In Hangzhou, Lao-cheng-qu is the main part of the built-up area before the foundation of the People's Republic of China in 1949, equal to administrative limits of Shangcheng and Xiacheng District in 1982 with the area of $13.45 \mathrm{sq} \mathrm{km}$. Aside from the core, there are another two important city zones: the inner suburb, with an area of $669.40 \mathrm{sq} \mathrm{km}$, refers to the municipality except for the core; and the outer suburb, with an area of 15,913.20 sq km, refers to the city region except for the core and the inner suburban, including seven counties.

\section{References}

1. Batty, M.; Longley, P.A. Fractal Cities: A Geometry of Form and Function; Academic Press: London, UK, 1994.

2. Frankhauser, P. La Fractalité des Structures Urbaines (The Fractal Aspects of Urban Structures); Economica: Paris, France, 1994.

3. White, R.; Engelen, G. Cellular automata and fractal urban form: A cellular modelling approach to the evolution of urban land-use patterns. Environ. Plan. A 1993, 25, 1175-1199. [CrossRef]

4. White, R.; Engelen, G.; Uljee, I. The use of constrained cellular automata for high-resolution modelling of urban-land dynamics. Environ. Plan. B 1997, 24, 323-343. [CrossRef]

5. Clark, C. Urban population densities. J. R. Stat. Soc. 1951, 114, 490-496. [CrossRef]

6. Batty, M.; Kim, K.S. Form follows function: Reformulating urban population density functions. Urban Stud. 1992, 29, 1043-1070. [CrossRef]

7. Chen, Y.G. A wave-spectrum analysis of urban population density: Entropy, fractal, and spatial localization. Discret. Dyn. Nat. Soc. 2008, 2008, 728420. [CrossRef]

8. Wang, F.H.; Zhou, Y.X. Modelling urban population densities in Beijing 1982-90: Suburbanisation and its causes. Urban Stud. 1999, 36, 271-287. [CrossRef]

9. Feng, J.; Wang, F.H.; Zhou, Y.X. Spatial Restructuring of Population in Beijing Metropolitan Area towards Polycentricity in the Post-Reform Era. Urban Geogr. 2009, 30, 779-802. [CrossRef]

10. Wang, F.H.; Meng, Y.C. Analyzing urban population change patterns in Shenyang, China 1982-90: Density function and spatial association approaches. Geogr. Inf. Sci. 1999, 5, 121-130. [CrossRef]

11. Xu, G.; Jiao, L.M.; Yuan, M. How does urban population density decline over time? An exponential model for Chinese cities with international comparisons. Landsc. Urban Plan. 2019, 183, 59-67. [CrossRef]

12. Luo, P.; Zhang, X.F.; Cheng, J.Y.; Sun, Q. Modeling population density using a new index derived from Multi-Sensor Image Data. Remote Sens. 2019, 11, 2620. [CrossRef]

13. Ren, H.; Guo, W.; Zhang, Z.; Kisovi, L.M.; Das, P. Population Density and Spatial Patterns of Informal Settlements in Nairobi, Kenya. Sustainability 2020, 12, 7717. [CrossRef]

14. Polinesi, G.; Recchioni, M.C.; Turco, R.; Salvati, L.; Rontos, K.; Rodrigo-Comino, J.; Benassi, F. Population trends and urbanization: Simulating density effects using a local regression approach. Int. J. Geo-Inf. 2020, 9, 454. [CrossRef]

15. Mariani, F.; Zambon, H.; Salvati, L. Population Matters: Identifying Metropolitan Sub-Centers from Diachronic Density-Distance Curves, 1960-2010. Sustainability 2018, 10, 4653. [CrossRef]

16. Qiang, Y.; Xu, J.W.; Zhang, G.H. The shapes of US cities: Revisiting the classic population density functions using crowdsourced geospatial data. Urban Stud. 2020, 57, 2147-2162.

17. Moghadam, A.S.; Soltani, A.; Parolin, B.; Alidadi, M. Analysing the space-time dynamics of urban structure change using employment density and distribution data. Cities 2018, 81, 203-213. [CrossRef]

18. Makse, H.A.; Havlin, S.; Stanley, H.E. Modelling urban growth patterns. Nature 1995, 377, 608-612. [CrossRef]

19. Newling, B.E. Urban growth and spatial structure: Mathematical models and empirical evidence. Geogr. Rev. 1966, 56, 213-225. [CrossRef]

20. Rozenfeld, H.D.; Rybski, D.; Andrade, D.S., Jr.; Batty, M.; Stanley, H.E.; Makse, H.A. Laws of population growth. Proc. Natl. Acad. Sci. USA 2008, 105, 18702-18707.

21. Kane, G. The mysteries of mass. Sci. Am. 2006, 15, 32-39. [CrossRef]

22. Henry, J. The Scientific Revolution and the Origins of Modern Science, 2nd ed.; Palgrave: New York, NY, USA, 2002.

23. Dendrinos, D.S. The Dynamics of Cities: Ecological Determinism, Dualism and Chaos; Routledge: London, UK; New York, NY, USA, 1992.

24. Rozenfeld, H.D.; Rybski, D.; Gabaix, X.; Makse, H.A. The area and population of cities: New insights from a different perspective on cities. Am. Econ. Rev. 2011, 101, 2205-2225. [CrossRef]

25. Schneider, A.; Seto, K.C.; Webster, D.R. Urban growth in Chengdu, Western China: Application of remote sensing to assess planning and policy outcomes. Environ. Plan. B Plan. Des. 2004, 32, 323-345. [CrossRef] 
26. Long, Y.G.; Chen, Y.G. Multi-scaling allometric analysis of the Beijing-Tianjin-Hebei urban system based on nighttime light data. Prog. Geogr. 2019, 38, 88-100.

27. Zeng, C.Q.; Zhou, Y.; Wang, S.X.; Yan, F.L.; Zhao, Q. Population spatialization in China based on night-time imagery and land use data. Int. J. Remote Sens. 2011, 32, 9599-9620.

28. Feng, J.; Chen, Y.G. Spatiotemporal evolution of urban form and land use structure in Hangzhou, China: Evidence from fractals. Environ. Plan. B Plan. Des. 2010, 37, 838-856. [CrossRef]

29. Lu, Y.M.; Tang, J.M. Fractal dimension of a transportation network and its relationship with urban growth: A study of the Dallas-Fort Worth area. Environ. Plan. B Plan. Des. 2004, 31, 895-911. [CrossRef]

30. Batty, M. New ways of looking at cities. Nature 1995, 377, 574.

31. Makse, H.A.; Andrade, J.S., Jr.; Batty, M.; Havlin, S.; Stanley, H.E. Modeling urban growth patterns with correlated percolation. Phys. Rev. E 1998, 58, 7054-7062. [CrossRef]

32. Manrubia, S.C.; Zanette, D.H.; Solé, R.V. Transient dynamics and scaling phenomena in urban growth. Fractals 1999, 7, 1-8. [CrossRef]

33. Peterson, I. The shapes of cities: Mapping out fractal models of urban growth. Sci. News 1996, 149, 8-9.

34. Man, X.M.; Chen, Y.G. Fractal-based modeling and spatial analysis of urban form and growth: A case study of Shenzhen in China. ISPRS Int. J. Geo-Inf. 2020, 9, 672.

35. Arbesman, S. The Half-Life of Facts: Why Everything We Know Has An Expiration Date; Penguin Group: New York, NY, USA, 2012.

36. Zhou, Y.X. Urban Geography; Commercial Press: Beijing, China, 1995. (In Chinese)

37. Chen, Y.G. A new model of urban population density indicating latent fractal structure. Int. J. Urban Sustain. Dev. 2010, 1, 89-110. [CrossRef]

38. Mcdonald, J.F. Econometric studies of urban population density: A survey. J. Urban Econ. 1989, 26, 361-385. [CrossRef]

39. Sherratt, G.G. A model for general urban growth. In Management Sciences, Model and Techniques: Proceedings of the Sixth International Meeting of Institute of Management Sciences; Churchman, C.W., Verhulst, M., Eds.; Pergamon Press: New York, NY, USA, 1960; Volume 2, pp. 147-159.

40. Tanner, J.C. Factors Affecting the Amount Travel. Road Research Technical Paper (No.51); HMSO (Department of Scientific and Industrial Research): London, UK, 1961.

41. Smeed, R.J. The Traffic Problem in Towns; Manchester Statistical Society Papers; Norbury Lockwood: Manchester, UK, 1961.

42. Parr, J.B. A population-density approach to regional spatial structure. Urban Stud. 1985, 22, 289-303. [CrossRef]

43. Longley, P.; Mesev, V. Beyond analogue models: Space filling and density measurements of an urban settlement. Pap. Reg. Sci. $1997,76,409-427$.

44. Newling, B.E. The spatial variation of urban population densities. Geogr. Rev. 1969, 59, 242-252. [CrossRef]

45. Latham, R.F.; Yeates, M.H. Population density growth in Metropokitan Toronto. Geogr. Anal. 1970, 2, 177-185. [CrossRef]

46. Cadwallader, M.T. Urban Geography: An Analytical Approach; Prentice Hall: Upper Saddle River, NJ, USA, 1996.

47. King, L.J.; Golledge, R.G. Cities, Space, and Behavior: The Elements of Urban Geography; Prentice Hall: Englewood Cliffs, NJ, USA, 1978.

48. Parr, J.B.; O'Neill, G.J. Aspects of lognormal function in the analysis of regional population distribution. Environ. Plan. A 1989, 21, 961-973. [CrossRef]

49. Muth, R. Cities and Housing: The Spatial Patterns of Urban Residential Land Use; Unversity of Chargo Press: Chicago, IL, USA, 1969.

50. Mills, E.S. Studies in the Structure of the Urban Economy; Johns Hopkins University Press: Baltimore, MD, USA, 1972.

51. Bussiere, R.; Snickers, F. Derivation of the negative exponential model by an entropy maximizing method. Environ. Plan. A 1970, 2, 295-301. [CrossRef]

52. Chen, Y.G. The rank-size scaling law and entropy-maximizing principle. Phys. A Stat. Mech. Its Appl. 2012, 391, 767-778. [CrossRef]

53. Feng, J.; Zhou, Y.X. Suburbanization and the changes of urban internal spatial structure in Hangzhou, China. Urban Geogr. 2005, 25, 107-136. [CrossRef]

54. Kong, X.Y.; Dong, W. Study on the evolution process and spatial integration of historical city centre area: Taking the conceptual urban design of Wulin Square and surrounding areas in Hangzhou as an example. Urban Archit. 2006, 12, 42-45. (In Chinese)

55. Zhang, Z.L. Research on the Spatiotemporal Effect of Urban Center on Housing Price. Master's Thesis, Zhejiang University, Hangzhou, China, 2012. (In Chinese).

56. Chu, L.H. Spatiotemporal Effects of Urban Spatial Structure on Housing Prices. Master's Thesis, Zhejiang University, Hangzhou, China, 2018. (In Chinese).

57. Su, M.K. Principle and Application of System Dynamics; Shanghai Jiao Tong University press: Shanghai, China, 1988. (In Chinese)

58. Zhao, C.Y.; Zhan, Y.H. Foundation of Control Theory; Tsinghua University press: Beijing, China, 1991. (In Chinese)

59. Haggett, P.; Cliff, A.D.; Frey, A. Locational Analysis in Human Geography; Edward Arnold: London, UK, 1977.

60. Taylor, P.J. Quantitative Methods in Geography; Waveland Press: Prospect Heights, IL, USA, 1983.

61. Shelberg, M.C.; Moellering, H.; Lam, N. Measuring the fractal dimensions of empirical cartographic curves. Auto Cart. 1982, 5 , 481-490.

62. Silver, N. The Signal and the Noise: Why Most Predictions Fail but Some Don't; Penguin Press: London, UK; New York, NY, USA, 2012.

63. Tang, X.F. Two worlds in geography. Book City 2009, 17, 15-20. (In Chinese) 
64. Batty, M. Space, scale, and scaling in entropy maximizing. Geogr. Anal. 2010, 42, 395-421. [CrossRef]

65. Batty, M.; Morphet, R.; Masucci, P.; Stanilov, K. Entropy, complexity, and spatial information. J. Geogr. Syst. 2014, 16, 363-385. [CrossRef]

66. Wilson, A.G. Modelling and systems analysis in urban planning. Nature 1968, 220, 963-966. [CrossRef]

67. Wilson, A.G. Entropy in urban and regional modelling: Retrospect and prospect. Geogr. Anal. 2010, 42, 364-394. [CrossRef]

68. Batty, M. Less is more, more is different: Complexity, morphology, cities, and emergence. Environ. Plan. B 2000, 27, 167-168. [CrossRef]

69. Hangzhou's statistics Bureau. Hangzhou Statistical Yearbook 1996; China Statistics Press: Beijing, China, 1997. (In Chinese)

70. Hangzhou's statistics Bureau. Hangzhou Statistical Yearbook 2005; China Statistics Press: Beijing, China, 2006. (In Chinese)

71. Zhou, Y.X.; Ma, L.J.C. Economic restructuring and suburbanization in China. Urban Geogr. 2000, 21, 205-236. [CrossRef]

72. Benguigui, L.; Czamanski, D.; Marinov, M.; Portugali, Y. When and where is a city fractal? Environ. Plan. B 2000, 27, 507-519. [CrossRef]

73. Benguigui, L.; Czamanski, D.; Marinov, M. City growth as a leap-frogging process: An application to the Tel-Aviv metropolis. Urban Stud. 2001, 38, 1819-1839. [CrossRef]

74. Krone, R.M. Systems Analysis and Policy Sciences; John Wiley \& Sons: New York, NY, USA, 1980.

75. Forrester, J.W. Urban Dynamics; MIT Press: Cambridge, MA, USA, 1969.

76. Chen, Y.G. The evolution of Zipf's law indicative of city development. Phys. A 2016, 443, 555-567. [CrossRef]

77. Mills, E.S.; Tan, J.P. A comparison of urban population density functions in developed and developing countries. Urban Stud. 1980, 17, 313-321. [CrossRef]

78. Batty, M.; Fotheringham, A.S.; Longley, P.A. Urban growth and form: Scaling, fractal geometry and diffusion-limited aggregation. Environ. Plan. A 1989, 21, 1447-1472. [CrossRef]

79. Fotheringham, S.; Batty, M.; Longley, P. Diffusion-limited aggregation and the fractal nature of urban growth. Pap. Reg. Sci. Assoc. 1989, 67, 55-69. [CrossRef]

80. Tobler, W. A computer movie simulating urban growth in the Detroit region. Econ. Geogr. 1970, 46, 234-240. [CrossRef] 